Revista lus et Praxis, Año 18, No 2, 2012, pp. 343 - 386

ISSN 0717 - 2877

Universidad de Talca - Facultad de Ciencias Jurídicas y Sociales

"La jurisprudencia del Consejo para la Transparencia sobre

acceso a la información pública y seguridad de la nación"

Pablo Contreras Vásquez

Andrés Pavón Mediano

\title{
LA JURISPRUDENCIA DEL CONSEJO PARA LA TRANSPARENCIA SOBRE ACCESO A LA INFORMACIÓN PÚBLICA Y SEGURIDAD DE LA NACIÓN*
}

\author{
Pablo Contreras VÁsquez ${ }^{* *}$ \\ Andrés Pavón Mediano ***
}

\section{INTRODUCCIÓN}

La transparencia se ha convertido en uno de los tópicos más relevantes de la discusión pública en Chile durante el último tiempo. Dentro de sus múltiples aristas, el Consejo para la Transparencia (en adelante, "CplT" o "Consejo") ha sido el organismo público que ha liderado una ruta de acceso a la información pública en manos de la administración del Estado. Sus decisiones han ido concretizando el contenido del derecho de acceso a la información y delimitado el contenido de las abstractas y vagas causales de reserva y secreto que lo limitan.

La doctrina del Derecho público ha estado atenta a los cambios ocasionados en materia de publicidad y transparencia. Desde el análisis del derecho de acceso a la información pública (en adelante, "DAIP") como derecho fundamental hasta los alcances de las decisiones de la Corte Interamericana de Derechos Humanos o el Tribunal Constitucional sobre la materia, los juristas nacionales se han ocupado de la fundamentación del derecho en sí y su recepción desde el

Los autores desean agradecer las precisiones y comentarios efectuados por los profesores Gonzalo García, Enrique Rajevic y Andrea Ruiz. Adicionalmente, desean agradecer a todos los participantes del "Seminario 3" organizado por la Universidad Alberto Hurtado el 27 de abril de 2012, donde se analizó un primer borrador de este texto. El resultado final es de exclusiva responsabilidad de los autores. Colaboración recibida el 12 de junio y aprobada el 22 de octubre de 2012.

Licenciado en Ciencias Jurídicas y Sociales, Universidad Alberto Hurtado. Abogado. Magíster en Gobierno y Sociedad, Universidad Alberto Hurtado. Master en Derecho (LL.M.), Mención en Derecho Internacional de los Derechos Humanos, Northwestern University. Candidato a Doctor en Derecho (S.J.D.), Northwestern University. Investigador asociado de la Universidad Alberto Hurtado. Correo electrónico: pcontreras@nlaw.northwestern.edu.

Licenciado en Ciencias Jurídicas y Sociales, Universidad Alberto Hurtado. Abogado. Analista de la Unidad de Reclamos del Consejo para la Transparencia. Correo electrónico: pavon.andres@gmail. com. 
punto de vista constitucional e internacional. ${ }^{1}$ Tal cuestión puede ser declarada pacífica y resuelta en la dogmática nacional. La aplicación concreta del DAIP y su articulación en relación a las causales de reserva o secreto, sin embargo, plantea un nuevo escenario de investigación y análisis. La fisonomía definitiva del derecho dependerá, en gran medida, de la aplicación que hagan del mismo los operadores y, significativamente, de las decisiones del CpIT resolviendo amparos de acceso a la información pública. La literatura especializada requiere poner atención al contenido de las decisiones y la dinámica de los operadores en la definición de los contenidos del DAIP y la delimitación de las causales de reserva o secreto.

Esta investigación, por tanto, inaugura esta nueva línea de análisis y contribuye a consolidar los elementos centrales del DAIP. Para ello, sistematiza y desarrolla presupuestos doctrinales y jurisprudenciales aplicables en la procedencia de causales de reserva o secreto cuando dicen relación con el resguardo de la seguridad de la Nación. El estudio presta atención a la jurisprudencia del CplT y las Cortes de Apelaciones al resolver amparos de acceso, con el objeto de identificar los elementos, requisitos y cargas de la prueba procedentes en la denegación de información. Luego se propone una agrupación de casos para identificar las líneas jurisprudenciales más claras y la diferencia entre las distintas materias que pueden ser susceptibles de secreto o reserva.

El texto sigue la siguiente estructura. En primer lugar, repasa el estatus de derecho fundamental que tanto la doctrina como la jurisprudencia ha otorgado al DAIP en nuestro país (II). Esta sección acredita que dicho estatus se encuentra plenamente asentado y que cumple un rol central en la jurisprudencia del CpIT. A continuación, se propone una sistematización de los presupuestos procedentes en la denegación de información por aplicación de causales de reserva o secreto que afecten la seguridad de la Nación (III). Este desarrollo doctrinal se construye principalmente a partir de la jurisprudencia del Consejo y de las Cortes, prestando atención a las contribuciones de la literatura. En primer lugar, se analiza el contenido normativamente protegido del DAIP, especialmente, en lo que dice con el derecho de petición y la información inexistente o expurgada (III.1). En segundo lugar, se revisa la exigencia de la invocación de una regla de secreto válida, según las condicionantes constitucionales y las modulaciones exigidas por el CpIT (III.2). Tercero, se explica el requisito de subsunción del objeto de la información solicitada a una causal de reserva o secreto establecida en una regla válida (III.3). Finalmente, para calificar una información como reservada o secreta, el servicio público debe acreditar que su divulgación afecta o genera un daño a la seguridad de la Nación. El último presupuesto, entonces,

${ }^{1}$ Véase infra II. 
trata el denominado test de daño (III.4). El texto examina a continuación los casos resueltos por la jurisprudencia en la materia, agrupándolos con fines de consulta futura. En esta sección, se analizan las decisiones sobre inexistencia y eliminación de información (IV.1); sobre plantas y personal de las Fuerzas Armadas y Carabineros de Chile (IV.2); sobre juntas de calificación (IV.3); sobre información financiera de la Defensa y aplicación de la Ley Reservada del Cobre (IV.4); sobre contratos y procesos de adquisición de pertrechos militares (IV.5); y las que dicen relación sobre operaciones militares (IV.6).

La investigación concluye extrayendo las principales contribuciones de la jurisprudencia sobre la aplicación de causales de reserva o secreto en materia de seguridad de la Nación.

\section{El DERECHO DE ACCESO A LA INFORMACIÓN PÚBLICA COMO DERECHO FUNDAMENTAL}

La calidad de derecho fundamental del derecho de acceso a la información pública ha sido reconocida tanto por la doctrina como por la jurisprudencia nacional e internacional. ${ }^{2}$ Por el lado de la dogmática constitucional y administrativa, se trata de un planteamiento que se ha consolidado en los últimos años, en el que confluyen distintos tipos de argumentos y que ya hemos tratado en detalle en otra parte. ${ }^{3}$ Baste aquí señalar que se entiende que el DAIP tiene

\footnotetext{
${ }^{2}$ Véase, por todos, Olmedo, Juan Pablo, "Comentarios Acerca del Derecho de Acceso a Información Pública", en VVAA, Hacia una Nueva Institucionalidad de Acceso a la Información Pública en Chile, Fundación Pro Acceso, Santiago, 2008, p. 13. Otros autores se refieren al punto con distintos argumentos: DíAz de VALDÉs, Juan Manuel, "Una Visión del Combate a la Corrupción centrada en los Derechos Fundamentales: El Derecho de Acceso a la Información Pública y su nueva Regulación Legal", en Romero, Juan José; Rodríguez, Nicolás y Olivares, José Miguel (eds.), Buen Gobierno y Corrupción, Pontificia Universidad Católica, Santiago, 2009, pp. 193 y ss.; RAJEVIC, Enrique, "La Jurisprudencia Inicial del Consejo para la Transparencia", Revista de Derecho (Consejo de Defensa del Estado) № 22, 2009, pp. 41-7; Tello, Cristóbal; Cerna, Marcelo y Pavón, Andrés, "Acceso a la Información Pública: Los Desafíos del Consejo de la Transparencia", Anuario de Derechos Humanos (Universidad de Chile), № 5 , 2009, pp. 195-6; García, Gonzalo y Contreras, Pablo, "Derecho de Acceso a la Información en Chile: Nueva Regulación e Implicancias para el Sector de la Defensa Nacional", Estudios Constitucionales Vol. 7, № 1, 2009, pp. 140-145. José Luis Cea lo trata, en su manual, como parte de la libertad de información y opinión. Véase a CEA, José Luis, Derecho Constitucional Chileno. Tomo II: Derechos, Deberes y Garantías, Ediciones Universidad Católica de Chile, Santiago, 2004, pp. 370-373. Existen algunos autores que son cautos frente a este tipo de reconocimiento de normas de derecho fundamental. En lo que se refiere al DAIP, Aldunate es uno de ellos. Véase a AldunAte, Eduardo, Derechos Fundamentales (Santiago, LegalPublishing, 2008), pp. 346-347. Para su reconocimiento iusfundamental en el Derecho comparado, véase por todos, MENDEL, Toby, Libertad de Información. Comparación Jurídica, UNESCO, París, Francia, 2008, $2^{\mathrm{a}}$ ed., passim.

${ }^{3}$ García y Contreras, "Derecho de Acceso", cit. n. 2, pp. 140-145; Contreras, Pablo, "Transparencia y Leyes Secretas en Chile", Estudios Constitucionales, Vol. 8, № 2, 2010, pp. 109-11; Tello, Cerna y Pavón, "Acceso", cit. n. 3, 195-6.
} 
protección constitucional e internacional -a través del sistema interamericanorespecto de la prestación que debe efectuar el Estado de información que se presume prima facie pública.

A su vez, la jurisprudencia constitucional ha reiterado, en diversas ocasiones, el estatus de un derecho constitucional "implícito". ${ }^{4}$ En palabras del Tribunal Constitucional (en adelante "TC"), "es posible afirmar que el derecho de acceso a la información pública se encuentra reconocido en la Carta Fundamental -aunque no en forma explícita- como un mecanismo esencial para la vigencia plena del régimen democrático $[\ldots]^{\prime \prime}$. A continuación señala que "acorde a la naturaleza del derecho reconocido por la Constitución que tiene el acceso a la información pública, aunque lo sea de forma implícita, la propia Carta Fundamental ha reservado a la ley [...] el establecimiento de las causales de secreto o de reserva $[\ldots]^{\prime \prime}$.

Finalmente, desde el punto de vista de las obligaciones internacionales, la Corte Interamericana de Derechos Humanos ha considerado que el acceso a la información pública constituye parte del contenido protegido de la libertad de expresión. En un fallo contra Chile, consideró que el artículo 13 de la Convención Americana de Derechos Humanos:

"al estipular expresamente los derechos a "buscar" y a "recibir" "informaciones", protege el derecho que tiene toda persona a solicitar el acceso a la información bajo el control del Estado, con las salvedades permitidas bajo el régimen de restricciones de la Convención. Consecuentemente, dicho artículo ampara el derecho de las personas a recibir dicha información y la obligación positiva del Estado de suministrarla, de forma tal que la persona pueda tener acceso a conocer esa información o reciba una respuesta fundamentada cuando por algún motivo permitido por la Convención el Estado pueda limitar el acceso a la misma para el caso concreto. Dicha información debe ser entregada sin necesidad de acreditar un interés directo para su obtención o una afectación personal, salvo en los casos en que se aplique una legítima restricción. Su entrega a una persona puede permitir a su vez que ésta circule en la sociedad de manera que pueda conocerla, acceder a ella y valorarla. De esta forma, el derecho a la libertad de pensamiento y de expresión

\footnotetext{
${ }^{4}$ Sentencia del Tribunal Constitucional (en adelante "STC"), Rol No 634-2007, 9 de agosto de 2007; STC Roles $\mathrm{N}^{\circ}$ s. 1732-10 y 1800-10 (acumuladas), 26 de junio de 2011. Acerca del reconocimiento de derechos constitucionales no explícitos en la Carta Fundamental, existen otros pronunciamientos: véase STC, Rol No 226-95, 30 de octubre de 1995, relativa al derecho a recibir informaciones (cons. 19º y la STC 1340-2009, 29 de septiembre de 2009, sobre el derecho a la identidad personal (cons. $9^{\circ}$ ). En doctrina, véase Contreras, Pablo, “¿Derechos Implícitos? Notas sobre la Identificación de Normas de Derecho Fundamental", en Núñez, José Ignacio (coord.), Nuevas Perspectivas en Derecho Público, Editorial Librotecnia, Santiago, 2011, pp. 149-183.
}

${ }^{5}$ STC, Rol No 634-2007, 9 de agosto de 2007, cons. $9^{\circ}$ (énfasis agregado).

${ }^{6}$ STC, Rol № 634-2007, 9 de agosto de 2007, cons. $10^{\circ}$ (énfasis agregado). 
contempla la protección del derecho de acceso a la información bajo el control del Estado, el cual también contiene de manera clara las dos dimensiones, individual y social, del derecho a la libertad de pensamiento y de expresión, las cuales deben ser garantizadas por el Estado de forma simultánea"7.

Se trata de una decisión que adopta una versión fuerte respecto del contenido protegido de la libertad de expresión, abarcando las facultades de acceso a la información pública. La protección internacional del derecho se ha dado también, con otros fundamentos y matices, en el ámbito europeo ${ }^{8}$. En el caso chileno, no sólo es vinculante la decisión de la Corte Interamericana, sino que define los márgenes de acción que tienen los órganos del Estado en la configuración legal y en la aplicación judicial del derecho en cuestión.

Volviendo al ámbito interno, el CpIT ha asumido, en múltiples decisiones, el consenso sobre la calidad de derecho fundamental del acceso a la información pública. Como revisaremos, tal consideración tiene importantes implicancias en la resolución de los casos de solicitudes de amparo en materia de información pública. Habrá que señalar que, desde temprano, el CplT reconoció el carácter de derecho fundamental. Será a propósito de un caso sobre reglas de secreto en materia de seguridad de la Nación que el Consejo definirá su posición al respecto. Nuestra exposición diseñará, a partir de la jurisprudencia del CplT, el conjunto de presupuestos generales aplicables a la denegación de información pública como ejercicio de restricción del DAIP. Primero expondremos los cuatro presupuestos aplicables y luego detallaremos los grupos de casos en los que se han ido desarrollando.

\section{LOS PRESUPUESTOS JURISPRUDENCIALES DE}

LIMITACIÓN DEL DERECHO DE ACCESO A LA INFORMACIÓN PÚBLICA

La relevancia que tiene el reconocimiento del estatus de derecho fundamental del DAIP impacta en la construcción del conjunto de presupuestos para la aplicación de causales de reserva o secreto como medidas restrictivas de un derecho fundamental. En ese sentido, se ha entendido que la reserva o secreto constituiría una limitación a un derecho fundamental. En segundo lugar, tal restricción del derecho tiene como fundamento la protección ya

${ }^{7}$ Corte Interamericana de Derechos Humanos, Claude Reyes et al. v. Chile, 19 de septiembre de 2006, Serie C, No 151, 2006, §77.

${ }^{8}$ Para una comparación entre el régimen interamericano y el europeo, en materia del DAIP, véase Contreras, Pablo, Acceso a la Información Pública y Seguridad de la Nación, Tesis para Optar al Grado de Magíster en Gobierno y Sociedad, Universidad Alberto Hurtado, Santiago, Inédito, 2010, pp. 3238. Con jurisprudencia actualizada sobre el caso europeo, véase MENDEL, Libertad de Información, cit. n. 2, pp. 15-7. 
sea de un derecho fundamental -como la vida privada o los datos personales de un tercero ${ }^{9}$ - o de bienes colectivos de rango constitucional -como es el debido ejercicio de las funciones de un órgano, la seguridad de la Nación o el interés nacional $-^{10}$.

Asimismo, la evaluación de la reserva o secreto de la información se determina verificando ciertos presupuestos que pueden ser correlacionados con una teoría general de límites a los derechos fundamentales. ${ }^{11}$ En relación al DAIP, estos presupuestos son los siguientes: primero, la determinación del contenido protegido del DAIP en relación a la solicitud de información, es decir, si lo que el particular requiere se encuentra protegido por el derecho en cuestión; segundo, la verificación de una causal de reserva o secreto establecida por ley de quórum calificado; tercero, la subsunción de la información denegada en la causal establecida en la ley; finalmente, la aplicación del test de daño para determinar la procedencia de la reserva o secreto. Cabe destacar que el CplT no ha sido del todo esquemático en la aplicación de estos presupuestos, cuestión que puede ser explicada por lo reciente del desarrollo de su cuerpo jurisprudencial. Empero, la sistematización de sus requisitos aportaría a la seguridad y certeza en las decisiones de amparo de información pública. Trataremos por separado cada presupuesto y su aplicación jurisprudencial.

\footnotetext{
${ }^{9}$ Sobre esto, el CplT ha avanzado en reconocer el derecho a la "autodeterminación informativa", en tanto vertiente positiva del derecho a la vida privada, el cual confiere un "poder de control sobre la información propia"; lo que encontraría fundamento en la Historia de la Ley № 19.628, sobre protección de la vida privada, que "es clara en reconocer que el régimen de protección de datos personales tiene por objeto la protección del 'derecho a la autodeterminación informativa', aun cuando el legislador optó por obviar su reconocimiento expreso en su artículo $1^{\circ}$, en tanto se trataba de un 'concepto doctrinario aún no suficientemente asentado'. Lo que el proyecto de ley que modifica las Leyes № 19.628 y № 20.285 busca enmendar (Boletín № 6120-07)." CplT C315-11, de 10 de mayo de 2011, "Contreras Concha con Ministerio de Vivienda y Urbanismo" (amparo de acceso a la información pública), cons. 4. También véase CpIT C532-11, de 24 de agosto de 2011, "Embotelladora Andina con Dirección del Trabajo" (amparo de acceso a la información pública); CpIT C416-11, de 14 de julio de 2011, "Narváez con Gendarmería de Chile" (amparo de acceso a la información pública); y CpIT C195-11, de 5 de julio de 2011, "García Ainol con Carabineros de Chile" (amparo de acceso a la información pública). (En adelante, las citas a decisiones del CplT deberán entenderse referidas a decisiones de amparo de acceso a la información pública, a menos que se exprese lo contrario).

${ }^{10}$ García y Contreras, "Derecho de Acceso", cit. n. 2, pp. 147-8; Contreras, Pablo, "Ponderación entre el Derecho de Acceso a la Información Pública y el Resguardo de la Seguridad de la Nación", en Letelier, Raúl y RAJEVIC, Enrique (coords.), Transparencia en la Administración Pública, LegalPublishing, Santiago de Chile, 2010.

${ }^{11}$ Véase, en general, a García, Gonzalo, Teoría Constitucional sobre los Límites al Ejercicio de los Derechos Fundamentales, Tesis para Optar al Grado de Doctor en Derecho, Universidad Carlos III, Inédita, Getafe, 2005.
} 


\section{Primer presupuesto: \\ Delimitación del contenido protegido del DAIP}

El primer presupuesto en materia de acceso a la información pública corresponde a la delimitación del contenido protegido por el derecho o, en otros términos, si el objeto de la solicitud de información se encuentra tutelado por la Constitución y la ley. El alcance del derecho ha sido establecido por la propia Ley de Transparencia, en términos amplísimos, mediante dos enunciados, a saber: (1) su artículo 10, según el cual "[e]l acceso a la información comprende el derecho de acceder [...] a toda información elaborada con presupuesto público, cualquiera sea el formato o soporte en que se contenga"; y (2) su artículo $5^{\circ}$, que establece el carácter público de "toda otra información que obre en poder de los órganos de la Administración, cualquiera sea su formato, soporte, fecha, clasificación o procesamiento". ${ }^{12}$

Esta noción amplia de la información pública ha sido desarrollada por el CplT, al menos, en dos sentidos. Primero, interpretando el concepto de información que "obra en poder" de la Administración del Estado, en términos tales que asegure la operatividad de la norma en el ámbito informático ${ }^{13}, y$, en según lugar, delimitando la frontera del DAIP frente al derecho de petición, para lo que ha relevando la exigencia de que la información solicitada obre en un soporte material o electrónico determinado, como condición de su entrega. En este último sentido, el CpIT ha concluido que "la información cuya entrega puede ordenar debe contenerse 'en actos, resoluciones, actas, expedientes, contratos y acuerdos' o en un 'formato o soporte' determinado, según reza el inciso $2^{\circ}$ del artículo 10 de la Ley de Transparencia, no pudiendo requerirse la entrega de información que sólo está en la mente de la autoridad"14. Sin perjuicio de

\footnotetext{
${ }^{12}$ Para una revisión sistemática de la noción de información pública en la jurisprudencia administrativa previa a la Ley No 20.285, véase CoRDERo VeGA, Luis, "Delimitando la Ley de Acceso a la Información: Los dilemas tras la regulación", en Letelier, Raúl y RAJeVIC, Enrique (eds.), Transparencia en la Administración Pública, LegalPublishing, Santiago, 2010.

${ }^{13}$ En CplT C457-10, de 16 de noviembre de 2010, "Narváez con Ministerio del Interior", el Consejo concluyó que la expresión "obrar en poder" "comprende no sólo aquella información que existe físicamente en las dependencias de un órgano de la Administración [según ordena el contenido literal de la voz 'obrar'] sino también aquella que el órgano mantiene en los hechos bajo su órbita de control o bajo su disposición -cualquiera sea su formato o soporte-, con el objeto de disponer potencialmente de ella para los fines que estime pertinente [conforme exige la inteligencia de la voz 'poder']" (cons. 13). También véase CpIT C790-11, de 23 de noviembre de 2011, "Rincón González con Ministerio de Transporte".

${ }^{14}$ CpIT C533-09, de 6 de abril de 2010, "Karadima Fariña con Universidad de Santiago de Chile", cons. $11^{\circ}$. De lo contrario -concluye el CplT en la citada decisión- "la solicitud no está cubierta por dicha ley sino que pasa a ser una manifestación del legítimo ejercicio del derecho de petición -establecido en el art. $19 \mathrm{~N}^{\circ} 14$ de la Carta Fundamental-, a tramitarse según las normas legales específicas que puedan existir o, en su defecto, según las disposiciones de la ya citada Ley № 19.880, de 2003, atendido su
} 
reconocer como excepción que la solicitud verse sobre "si se realizó o no una acción que habría acaecido en el pasado ${ }^{\prime \prime 5}$ ( $v$. gr., si la autoridad ha verificado la existencia de la infraestructura requerida para dar factibilidad legal a un proyecto aprobado ambientalmente ${ }^{16}$ ), caso en el cual ésta si estaría cubierta por el contenido protegido del DAIP. Ello es sin perjuicio de que el Consejo, de conformidad con su interpretación de la historia fidedigna de la Ley $N^{\circ} 20.285$, ha concluido que frente a determinadas consultas ante la autoridad, el DAIP permite "solicitar a los órganos de la Administración elaborar documentos, en tanto la información que allí se vuelque obre en poder de la Administración y con un límite financiero: no irrogar al Servicio un costo excesivo o un gasto no previsto en el presupuesto institucional"17.

La exigencia de que la información solicitada obre en un soporte determinado, importa que la tutela actual del DAIP encuentre como desafíos centrales el adecuado registro, conservación y control de la destrucción de la información en poder de los órganos administrativos. En otras palabras, la posibilidad material de registro y conservación permite ejercer el derecho, mientras que la destrucción de información lo impide. En consecuencia, de ello dependerá que la mera alegación de la inexistencia de la documentación no constituya una restricción incontrarrestable al acceso a la información ${ }^{18}$.

EI CpIT ha sido perentorio en recurrir a los estándares de registro dispuestos por la Ley $\mathrm{N}^{\circ}$ 19.880, de Bases de Procedimiento Administrativo (LBGPA), al tiempo de revisar-con particular escepticismo- las alegaciones de inexistencia

valor supletorio". A modo ejemplar, véase CpIT C453-10, de 26 de noviembre de 2010, "Serani Mostazal con Carabineros de Chile", cons. 16 $6^{\circ}$, relativo a la solicitud de que se indique "conforme a qué ley las Unidades de Carabineros deben mantener un listado de empresas que proporcionen servicios de grúa", lo que el Consejo califica como la petición de una "opinión legal".

${ }^{15}$ CpIT C539-10, de 5 de octubre de 2010. "Quiroz Rocha con Municipalidad de Coronel", cons. $8^{\circ}$.

${ }^{16}$ CpIT C603-09 y C16-10 (acumuladas), de 14 de mayo de 2010, "Ruiz-Tagle con SEREMI de Vivienda y Urbanismo de la Región Metropolitana", cons. $7^{\circ}$.

${ }^{17}$ CplT A97-09, de 18 de agosto de 2009, "Urzúa Millán con Dirección de Vialidad del Ministerio de Obras Públicas", cons. $6^{\circ}$. Véase también CplT C819-11, de 7 de octubre de 2011, "Domínguez Pinto con Ministerio de Obras Pública"; y CplT C1038-11 y C1041-11 (acumuladas), de 28 de octubre de 2011, "Goldstein Vázquez con Presidencia de la República".

${ }^{18}$ En ese sentido, durante la tramitación legislativa de la Ley No 20.285, el entonces Presidente del Capítulo Chileno de Transparencia Internacional, Davor Harasic Y., recomendó se dispusiera que la denegación del acceso a la información debía efectuarse "mediante una declaración jurada del jefe del servicio, puesto que, en caso contrario, sería muy simple evadir la entrega basada en la inexistencia de la misma. La sugerencia tiene como finalidad preconstituir una prueba, puesto que si el funcionario que firma la declaración miente, podría incurrir en el delito de falsificación ideológica". BibloteCA del Congreso Nacional de Chile, Historia de la Ley № 20.285 sobre Acceso a la Información Pública, 20 de agosto de 2008, p. 349. Disponible en: http://www.bcn.cl/histley/lfs/hdl-20285/HL20285.pdf [visitado el 11/06/2012]. 
de los órganos administrativos, incluidas las Fuerzas Armadas y a las Fuerzas de Orden y Seguridad Pública ${ }^{19}$. Un ejemplo de este escepticismo encuentra expresión en "Lux Palma con Armada de Chile", donde se requería información sobre el procedimiento utilizado por la Armada para determinar qué personas viajarían a Valparaíso, a bordo del buque que evacuó a familiares del personal de la Armada desde Talcahuano, en el contexto del terremoto de 27 de febrero de 2010. En dicha decisión, si bien se reconoce que las circunstancias de excepcionalidad del procedimiento permiten presumir que éste se realizó "desformalizadamente", habiendo el Consejo constatado que la respuesta del organismo no fue clara en informar si se registró a pasajeros no vinculados a la Armada en el viaje ${ }^{20}$, éste resolvió forzar un pronunciamiento sobre el particular, ordenando entregar los documentos en que conste el registro de los familiares de personal de la Armada a bordo del buque e indicar expresamente si embarcó en él personas no vinculadas a la institución ${ }^{21}$.

Tratándose de la eliminación de información, el CpIT ha desempolvado la escueta regulación nacional sobre archivo y eliminación de documentos en poder de la Administración. Su piedra angular se encuentra en el añoso D.F.L. № 5.200, del Ministerio de Educación, que crea la Dirección de Bibliotecas Archivos y Museos, dictado en 1929, y la Circular No 28.704, de 1981, de la CGR, que sistematiza las principales disposiciones en la materia. En efecto, el citado cuerpo legal establece la obligación de los Subsecretarios -así como de otras autoridades- de ingresar anualmente al Archivo Nacional los documentos de sus Ministerios que hayan cumplido 5 años de antigüedad, a fin de asegurar su conservación, sancionando a quienes no den cumplimiento a esta disposición con la disuasiva multa de "diez pesos por cada día de atraso" (artículo 14). Por su parte, la Circular prescribe que la autorización para eliminar documentos compete al Presidente de la República y, en su caso, a la jefatura superior de los organismos con autonomía administrativa, mediante decreto o resolución

\footnotetext{
${ }^{19}$ La LBGPA dispone como principios orientadores de los procedimientos administrativos: su escrituración (artículo $5^{\circ}$ ); ordena que éstos consten "en un expediente, escrito o electrónico, en el que se asentarán los documentos presentados por los interesados, por terceros y por otros órganos públicos" (artículo 18, inciso $3^{\circ}$ ); y exige "dejar constancia indubitada de lo actuado" (artículo 13).

${ }^{20}$ CplT C652-10, de 23 de septiembre de 2010, "Lux Palma con Armada de Chile", cons. 5.

${ }^{21}$ CplT C652-10, cit. n. 20, cons. $8^{\circ}$. Ha sido conocido del acceso a información relativa al Proyecto Hidroeléctrico Aysén que el CpIT ha manifestado más enérgicamente su preocupación por la ausencia de registro de las actuaciones administrativas, advirtiendo sobre el alto grado de informalidad de los procedimientos de evaluación ambiental. Véase CpIT Roles C728-11, "Segura Ortiz con Dirección General de Aguas"; C729-11, "Segura Ortiz con Gobernación Provincial de General Carrera"; C734-11, "Segura Ortiz con Ministerio del Medio Ambiente"; y C751-11, "Segura Ortiz con Servicio Agrícola y Ganadero"; todas de 28 de septiembre de 2011.
} 
exenta de toma de razón, dejándose constancia en un acta levantada al efecto de la forma en que se le ha dado cumplimiento ${ }^{22}$.

Empero, en el ámbito de la defensa nacional, la única modificación de la que ha sido objeto del D.F.L. № 5.200 -adicionada por la Junta Militar, a través de la Ley $\mathrm{N}^{\circ} 18.771$, de 1989- excepcionó de las reglas precedentes a la documentación del Ministerio de Defensa Nacional, de las Fuerzas Armadas, de Orden y Seguridad Pública, y de los demás organismos dependientes de esa Secretaría de Estado o que se relacionen con el Gobierno por su intermedio. La documentación de estos organismo "se archivará y eliminará conforme a lo que disponga la reglamentación ministerial e institucional respectiva" (artículo 14, inciso final) y se encuentra exceptuada del régimen de conservación de microcopias establecido por la Ley $N^{\circ} 18.845$, sobre sistema de microscopia y micrograbación de documentos, lo que ha entregado a la discrecionalidad de las FF.AA. y de Orden Público "quién decide y con qué criterio la exclusión o eliminación de documentos" ${ }^{\prime \prime 2}$.

Como revisaremos en detalle en la sección de casos, el CpIT ha establecido tres criterios básicos aplicables a estas reglas sobre registro, conservación y destrucción de información en el sector de la Defensa Nacional. Primero, debe verificarse si el órgano recurrido es competente o tenía una obligación de poseer la información solicitada y, en el evento de no existir, debe responder dando cuenta de ello ${ }^{24}$. Segundo, el organismo debe acreditar-acompañando el respectivo acto administrativo- que se "expurgó" la información que ahora se declara inexistente ${ }^{25}$. Finalmente, en el evento que no se encuentre el acto administrativo que acredite la expurgación de la información, se acepta excepcionalmente que la respuesta del servicio cumple con la legislación si se efectuó una búsqueda exhaustiva de la misma ${ }^{26}$. Dichos criterios han sido

\footnotetext{
${ }^{22}$ En cuanto a la conservación de comunicaciones en soporte electrónico, véase el D.S. № 77, de 2004, del Ministerio Secretaría General de la Presidencia, norma técnica sobre eficiencia de las comunicaciones electrónicas entre órganos administrativos y entre estos y los ciudadanos. Por su parte, sobre la disposición del material de desechos de los órganos administrativos, véase el Título $\mathrm{V}$ del Decreto № 577, de 16 de agosto de 1978, del Ministerio de Tierras y Colonización, hoy de Bienes Nacionales, que regula el tratamiento de los bienes muebles fiscales.

${ }^{23}$ CAMACho CépedA, Gladys, "Algunas precisiones sobre el concepto de información pública", en Letelier, Raúl y Rajevic, Enrique (eds.), op. cit., p. 63. Véase también García y Contreras, "Derecho de Acceso", cit. n. 2, p. 156; Contreras, "Transparencia", cit. n. 3, p. 99.

${ }^{24}$ CplT C804-10, de 24 de febrero de 2011, "Gastón Pérez Viveros con Fuerza Aérea de Chile", cons. $4^{\circ}$. En similares términos, véase CpIT C52-10, de 9 de julio de 2010, "Superintendencia de Electricidad y Combustibles con Parada Sepúlveda".

${ }^{25}$ CplT C382-11, de 26 de febrero de 2010, "Skoknic Galdames con Ejército de Chile", cons. $5^{\circ}$.

${ }^{26}$ CpIT C804-10, cit. n. 24, cons. $9^{\circ}$. Una ratificación de estos estándares y el desarrollo de criterios de búsqueda de información puede encontrarse en CpIT C1179-11, de 25 de enero de 2011, "Insunza Rojas con Subsecretaría de Hacienda y Dirección de Presupuestos".
} 
sistematizados por el Consejo en su Instrucción General № 10, al regular el procedimiento administrativo de acceso a la información pública (publicada en el D.O. de 17.12.2011).

El primer presupuesto cumple la función de determinar el ámbito de aplicación de la Ley de Transparencia a ciertas solicitudes de información. No es usual que la Administración conteste una solicitud argumentando que no se dispone de la información, aunque la ausencia de estándares estrictos de prueba podría incentivar la apelación a ello. Por regla general, si no entrega la información es porque se aduce una causal de reserva o secreto. Los siguientes presupuestos se aplican a tal situación.

\section{Segundo presupuesto: reserva de ley de quórum calificado}

Tal como lo establece el artículo $8^{\circ}$ de la Constitución, la información que puede ser clasificada como reservada o secreto debe haber sido establecida por una ley de quórum calificado. Se trata de una especificación de la regla de reserva de ley en la regulación y limitación del principio de publicidad ${ }^{27}$. Este presupuesto no presenta mayores dificultades en la mayoría de las decisiones de acceso a información pública, puesto que el artículo 21 de la LT regula las causales de reserva y secreto que son usualmente aplicadas en las decisiones del $\mathrm{CplT}^{28}$ y tal precepto legal fue aprobado con el quórum exigido por la Constitución ${ }^{29}$, sin perjuicio de otras leyes que establecen causales de reserva o secreto ${ }^{30}$.

\footnotetext{
${ }^{27}$ García, Gonzalo, La Reserva Legal de Derechos Constitucionales, Universidad Alberto Hurtado, Colección de Investigación Jurídica № 5, Santiago, 2004, passim. Sobre el estado del debate en materia de reserva de ley, revísese a Zapata, Patricio, Justicia Constitucional. Teoría y Práctica en el Derecho Chileno y Comparado, Editorial Jurídica de Chile, Santiago, 2008, pp. 361-389.

${ }^{28}$ No sólo reglas legales de quórum calificado podría eventualmente aplicar el CpIT para denegar el acceso a la información. Al menos tres hipótesis alternativas podrían surgir. En primer lugar, cuando se trata de disposiciones constitucionales que autorizan el secreto o reserva de información, como es el caso del artículo 107, inciso $3^{\circ}$ de la Constitución, sobre el secreto de las actas del Consejo de Seguridad Nacional. Sobre las reglas constitucionales de secreto, como excepción al principio de publicidad, véase CONTRERAS, "Transparencia", cit. n. 3, p. 93. Una segunda hipótesis proviene de aquellas reglas establecidas en instrumentos internacionales que no gozan de rango legal. Esta posibilidad ha sido explorada por el CpIT, en CpIT C590-10, 30 de agosto de 2010, "Contreras Vásquez con Ministerio de Relaciones Exteriores", cons. $6^{\circ}$ y $8^{\circ}$. Por último, según hizo presente el TC citando a la doctrina, "existirán casos en que la confidencialidad es materia de ley orgánica constitucional". Sobre el particular, véase FERNÁNDEZ, Miguel. "El principio de publicidad de los actos estatales en el nuevo artículo $8^{\circ}$ inciso $2^{\circ}$ de la Constitución", en ZúÑIGA, Francisco (coord.), "Reforma Constitucional", Editorial Lexis Nexis, Santiago de Chile, 2005; y STC Rol No 634-2007, 9 de agosto de 2007, cons. $13^{\circ}$.

${ }^{29}$ Historia de la Ley $N^{\circ} 20.285$, cit. n. 10, pp. 488 y 498 (dejando constancia de que las votaciones efectuadas en la Cámara de Diputados y en el Senado cumplieron con el quórum establecido en la Constitución).

${ }^{30}$ Una regla especial, al respecto, se encuentra en la misma LT. El artículo 22 fija plazos para la desclasificación de información que se haya declarado reservada o secreta. Específicamente, se establece
} 
Sin embargo, la existencia de leyes anteriores a la reforma constitucional del 2005 -que estableció el nuevo artículo $8^{\circ}$ - ha generado la necesidad de analizar la validez de estas reglas. En materia de seguridad de la Nación, un número considerable de reglas que establecen el secreto militar o de defensa nacional se encuentran en leyes promulgadas con anterioridad al año $2005^{31}$.

Un antecedente relevante para ser considerado es el criterio que fijó la Contraloría General de la República (en adelante, CGR) sobre este punto. Revisando la validez del artículo 436 del Código de Justicia Militar ${ }^{32}$ (en adelante, CJM) -una de las reglas más utilizadas por la Administración para justificar la reserva o secreto de información- la CGR sostuvo que

"el artículo 436 del Código de Justicia Militar está amparado por la ficción de la disposición cuarta transitoria de la Carta Fundamental y, por ende, no ha sido derogado por el artículo $8^{\circ}$ de la Constitución, por lo que las autoridades institucionales pueden dictar, con el carácter de secretos, los actos en que inciden los documentos que menciona dicho artículo 436"33.

Tal interpretación administrativa ha sido constantemente citada para apoyar la constitucionalidad de leyes que establecen reglas de secreto dictadas anteriormente a la vigencia del nuevo artículo $8^{\circ}$. El órgano contralor se apoya, básicamente, en cuatro razones: (1) una interpretación literal de la disposición

que la reserva será "indefinida" respecto de información que, "en el ámbito de la defensa nacional, establezcan la planificación militar o estratégica, y de aquellos cuyo conocimiento o difusión puedan afectar:

a) La integridad territorial de Chile;

b) La interpretación o el cumplimiento de un tratado internacional suscrito por Chile en materia de límites;

c) La defensa internacional de los derechos de Chile, y

d) La política exterior del país de manera grave".

${ }^{31}$ El análisis de la validez formal y material de algunas de estas reglas lo efectuamos, antes de la entrada en vigencia de las funciones del CplT, en García y Contreras, "Derecho de Acceso", cit. n. 2, pp. 155-61.

32 "Art. 436. Se entiende por documentos secretos aquellos cuyo contenido se relaciona directamente con la seguridad del Estado, la Defensa Nacional, el orden público interior o la seguridad de las personas y entre otros:

1.- Los relativos a las Plantas o dotaciones y a la seguridad de las instituciones de las Fuerzas Armadas o de Carabineros de Chile y de su personal;

2.- Los atinentes a planos o instalaciones de recintos militares o policiales y los planes de operación o de servicio de dichas instituciones con sus respectivos antecedentes de cualquier naturaleza, relativos a esta materia;

3.- Los concernientes a armas de fuego, partes y piezas de las mismas, municiones, explosivos, sustancias químicas y demás efectos a que se refiere la Ley $\mathrm{N}^{\circ} 17.798$ usados por las Fuerzas Armadas o Carabineros de Chile, $y$

4.- Los que se refieran a equipos y pertrechos militares o policiales.".

${ }^{33}$ Dictamen de la CGR, № 48.302, 26 de octubre de 2007, §III (Conclusiones). 
$4^{\text {a }}$ transitoria de la Constitución ${ }^{34}$; (2) la necesidad de adoptar una concepción "dinámica y cambiante" del proceso de elaboración de normas jurídicas; (3) la finalidad de la disposición $4^{a}$ transitoria de la Constitución es la solución de antinomias y esta lógica se puede aplicar en términos generales y no circunscrita, exclusivamente, a normas que se dictaron previamente a la entrada en vigencia de la Constitución; (4) finalmente, se debe buscar evitar consecuencias perjudiciales para la integridad del ordenamiento jurídico ${ }^{35}$.

El CplT ha adoptado un criterio similar pero con un condicionamiento que exige una labor interpretativa significativamente importante. El Consejo ha entendido que la validez de las reglas legales anteriores a la reforma constitucional del 2005 debe ser examinada a la luz de lo dispuesto en el artículo $8^{\circ}$ de la Constitución. Si bien la disposición $4^{\text {a }}$ transitoria busca precaver las previsibles antinomias entre reformas constitucionales que elevan los quórum constitucionales, por un lado, y los preceptos legales dictados con anterioridad de dichas reformas, esto salvaría, únicamente, el problema formal del quórum. La disposición $4^{\mathrm{a}}$ transitoria dispone que se entienden que cumplen los requisitos formales de quórum, aquellas leyes actualmente en vigor sobre materias que conforme a la misma Constitución deben ser objeto de leyes orgánicas constitucionales o aprobadas con quórum calificado. Éstas deben seguir aplicándose y son válidas, "en lo que no sean contrarias a la Constitución, mientras no se dicten los correspondientes cuerpos legales". El correlato legal de tal disposición se encuentra en el artículo $1^{\circ}$ transitorio de la $\mathrm{LT}^{36}$.

Sin embargo, el CplT agrega que "[...] no toda norma legal previa a la Ley de Transparencia que fije un caso de secreto o reserva se entenderá automáticamente vigente: sólo aquellas que puedan reconducirse a las causales del artículo $8^{\circ}$ de la Constitución [... $]^{\prime \prime 37}$. En consecuencia, se ha establecido una exigencia de reconducción material de las normas pre-2005 a las causales constitucionales de reserva o secreto establecidas por la Constitución ${ }^{38}$. Se trata de un ejercicio

\footnotetext{
${ }^{34}$ La disposición 4 a transitoria señala: "Se entenderá que las leyes actualmente en vigor sobre materias que conforme a esta Constitución deben ser objeto de leyes orgánicas constitucionales o aprobadas con quórum calificado, cumplen estos requisitos y seguirán aplicándose en lo que no sean contrarias a la Constitución, mientras no se dicten los correspondientes cuerpos legales".

${ }^{35}$ Dictamen de la CGR, № 48.302, cit. n. 33, pár. 1-4.

${ }^{36}$ Artículo $1^{\circ}$ transitorio. "De conformidad a la disposición cuarta transitoria de la Constitución Política, se entenderá que cumplen con la exigencia de quórum calificado, los preceptos legales actualmente vigentes y dictados con anterioridad a la promulgación de la Ley $N^{\circ} 20.050$, que establecen secreto o reserva respecto de determinados actos o documentos, por las causales que señala el artículo $8^{\circ}$ de la Constitución Política".

${ }^{37}$ CplT A45-09, 28 de julio de 2009, "De la Carrera Valdés con Carabineros de Chile", cons. $3^{\circ}$.

${ }^{38}$ Es preciso señalar que el CpIT hace esta interpretación para efectos de la aplicación de los artículos $21 \mathrm{~N}^{\circ} 5$ y $1^{\circ}$ transitorio de la LT, que para denegar información exigen, respectivamente, que "se trate
} 
de interpretación conforme a la Constitución ${ }^{39}$. En dicha decisión, como revisaremos más adelante, el Consejo determinó que el orden público podía ser reconducido al contenido material del artículo $8^{\circ}$ de la Constitución bajo dos de sus causales de reserva o secreto: la seguridad de la Nación -en relación a lo dispuesto en el artículo $21 \mathrm{~N}^{\circ} 3 \mathrm{LT}-\mathrm{y}$ los derechos de las personas -en relación al numeral 2 del mismo precepto legal-. ${ }^{40}$ La exigencia jurisprudencial, sin embargo, obligará a la administración a argumentar la vigencia material de la norma en relación a las causales de reserva o secreto constitucionales. Es decir, una vez salvado el problema de validez formal -en relación al quórum de aprobación del precepto legal- la invocación del artículo 436 CJM demandará una labor interpretativa que justifique su contenido en relación a lo dispuesto por el artículo $8^{\circ}$. No sólo deberá reconducirse a la Constitución: como veremos más adelante, la administración deberá igualmente aplicar el test de daño para denegar la información, de manera de hacer compatible la exigencia de "afectación" de la seguridad de la Nación fijada por el artículo $8^{041}$.

Esta exigencia de reconducción material desechará las tesis radicales de invalidación de normas pre-2005, como lo era la derogación tácita. Este fue la principal cuestión jurídica a resolver en "Díaz Acuña con Fuerza Aérea de Chile $^{42}$. El solicitante requirió a la Fuerza Aérea que se le diese acceso a "Ios fundamentos que llevaron a la Junta Especial de Selección del Cuadro Permanente de la $\mathrm{FACH}$, a determinar la inclusión en la Lista de Retiros al reclamante" ${ }^{\prime \prime 3}$.

de documentos, datos o informaciones que una ley de quórum calificado haya declarado reservados o secretos, de acuerdo a las causales señaladas en el artículo $8^{\circ}$ de la Constitución Política"; y que "[s] e entenderá que cumplen con la exigencia de quórum calificado, los preceptos legales actualmente vigentes y dictados con anterioridad a la promulgación de la Ley $N^{\circ} 20.050$, que establecen secreto o reserva respecto de determinados actos o documentos, por las causales que señala el artículo $8^{\circ}$ de la Constitución Política" (el destacado es nuestro). Véase CplT C57-10, 2 de noviembre de 2010, "Donoso Salgado con Ministerio de Defensa Nacional", cons. 4'; y CpIT C349-11 y C536-11 (acumuladas), de 24 de agosto de 2011, "Weatherhaven Chile S.A. con Estado Mayor Conjunto", cons. 10 .

${ }^{39}$ El Tribunal Constitucional ha entendido la interpretación conforme a la Constitución como "un principio que consiste en buscar la interpretación de las normas que permita resolver, dentro de lo posible, la conformidad de una norma con la Constitución." (STC Rol 1209, 21 de octubre de 2008, cons. $1^{\circ}$ ). En nuestra dogmática, revísese a Ribera, Teodoro, "El Tribunal Constitucional y su Aporte al Desarrollo del Derecho", Estudios Públicos № 34, 1989, pp. 224-226. Refiriéndose a los efectos de la reforma al artículo $8^{\circ}$ de la Constitución y los problemas de inconstitucionalidad sobreviniente, véase a CoRDERo, Luis, "Efectos de la Reforma Constitucional en Materia de Acceso a la Información Pública", Revista de Derecho Público, Vol. 69, T. II, 2007, pp. 96-97 (exigiendo la interpretación conforme a la Constitución para estos casos y relegando la declaración de inconstitucionalidad sólo en el evento que la norma sea "inequívocamente contraria a la norma suprema").

${ }^{40}$ CplT A45-09, cit. n. 37, cons. $5^{\circ}$.

${ }^{41}$ Cfr. infra III, 3.

${ }^{42}$ CpIT A266-09, 15 de diciembre de 2009, "Díaz Acuña con Fuerza Aérea de Chile".

${ }^{43}$ CpIT A266-09, cit. n. 42, cons. $4^{\circ}$. 
Sin embargo, el artículo 26, inciso $6^{\circ}$ de la Ley Orgánica Constitucional de las Fuerzas Armadas (en adelante, LOC FF.AA.) establece que "[l]as sesiones y actas de las Juntas [de Selección y Apelación de las Fuerzas Armadas] serán secretas". Pese a lo dispuesto en el tenor literal de la ley, el recurrente argumentó que la norma en cuestión había sido derogada tácitamente por la reforma al artículo $8^{\circ}$ de la Constitución ${ }^{44}$. El organismo recurrido, por otra parte, citó los dictámenes de la CGR validando la compatibilidad de artículo 26 , inciso $6^{\circ}$ de la LOC FF.AA. con la Constitución ${ }^{45}$.

El Consejo descansa en gran parte en la argumentación del servicio, sin abundar en el punto de la derogación tácita de las normas pre-2005. ${ }^{46}$ En consecuencia, parece aceptar que la disposición en comento "no sólo se trataría de una ley aprobada con quórum orgánico constitucional [...], sino además, se encontraría vinculada con una de las causales del artículo $8^{\circ}$ de la Constitución que exceptúan la publicidad de la información, en particular, con la seguridad de la Nación" ${ }^{\prime 47}$. Sin perjuicio del rechazo de la tesis del solicitante, el problema parece no haberse zanjado argumentativamente, sino que sólo fue resuelto para el caso en concreto. Así, reitera el criterio de la CGR sobre la validez del artículo 26 LOC FF.AA., en concordancia con el artículo $8^{\circ}$ de la Constitución ${ }^{48}$ y, con estos antecedentes, el CplT estima que la información requerida "es reservada o secreta, debido a que se ha configurado fehacientemente la causal consagrada en el artículo $21 \mathrm{~N}^{\circ} 5$ de la Ley de Transparencia, no debiendo divulgarse [...], pues afectaría la seguridad de la Nación, como ya se ha demostrado a lo largo del presente procedimiento" ${ }^{\prime 4}$.

Con todo, en casos posteriores el Consejo ha ido especificando su exigencia de reconducción material de leyes pre-2005 al artículo $8^{\circ}$ de la Constitución. Un caso clave, al respecto, es "Narváez Almendras con Ejército de Chile"50. Se trataba de una solicitud de información respecto del personal que desempeñaba funciones de capellán de cualquier creencia religiosa al interior de las FF.AA., cuestión que fue negada en virtud de lo dispuesto en el artículo 436 $\mathrm{N}^{\circ} 1 \mathrm{CJM}^{51}$, en relación al artículo $21 \mathrm{~N}^{\circ} 5$ LT. El CplT admite que la vigencia

\footnotetext{
${ }^{44}$ CplT A266-09, cit. n. 42, cons. $6^{\circ}$.

${ }^{45}$ Véase los Dictámenes de la CGR, Nºs. 10.646, de 7 de marzo de 2008, y 13.318, de 26 de marzo de 2008.

${ }^{46}$ CplT A266-09, cit. n. 42, vistos $N^{\circ}$ s. 2-5.

${ }^{47}$ CplT A266-09, cit. n. 42, cons. $7^{\circ}$.

${ }^{48}$ CplT A266-09, cit. n. 42, cons. $8^{\circ}$.

${ }^{49}$ CplT A266-09, cit. n. 42, cons. $9^{\circ}$.

${ }^{50}$ CplT C512-09, 15 de enero de 2010, "Narváez Almendras con Ejército de Chile".

${ }^{51}$ CplT C512-09, cit. n. 50, cons. $3^{\circ}$.
} 
del artículo 436 ha sido reconocida por la $\mathrm{CGR}^{52}$ y comienza su argumentación señalando que "es necesario analizar también si el artículo 436 del Código de Justicia Militar se encuentra conforme a lo dispuesto en el artículo $8^{\circ}$ inciso $2^{\circ}$ de la Constitución, esto es, si la reserva allí establecida se funda en la afectación de la seguridad de la Nación" ${ }^{53}$. Al respecto, el Consejo destaca la frase "cuyo contenido se relaciona directamente con la seguridad del Estado" del artículo $436 \mathrm{CJM}$, por un lado, y la voz "afectare" del artículo $8^{\circ}$, inciso $2^{\circ}$ de la Constitución, por el otro ${ }^{54}$. A partir de ello, el Consejo determina que se "exige[,] como señala expresamente el precepto constitucional[,] que la publicidad de dicha información debe afectar la seguridad de la Nación, circunstancia que ha sido esgrimida por el Ejército de Chile en este caso" ${ }^{\prime \prime 5}$. Al encontrar entre dos exigencias de distinto grado -el "relacionarse" con la seguridad del Estado (artículo 436 CJM) y el "afectarse" la seguridad de la Nación (artículo 8, inciso $2^{\circ}$ de la Constitución)- el CplT decide armonizar disposiciones en base a una armonización interpretativa de la ley con la Constitución. Así, sostiene que

"[...] El vocablo "afectare" es claro en cuanto a que debe causarse un perjuicio o daño al bien jurídico si se divulga la información, de manera que no basta sólo que aquélla se "relacione" con éste o que le resulte atingente para que el legislador pueda mantener tal información en secreto o reserva. Esta es la forma, a juicio de este Consejo, en que la aludida disposición del Código de Justicia Militar debe ser interpretada para obtener un resultado que sea conforme con el texto vigente de la Constitución" ${ }^{\prime \prime 6}$.

De esta forma, para el Consejo no basta invocar la disposición $4^{a}$ transitoria para aplicar una regla pre-2005 en materia de acceso a la información. Ni siquiera basta ampararse en la interpretación de la CGR sobre este mismo punto. Según la exigencia de interpretación conforme a la Constitución, la Administración que busque denegar información en base a una regla anterior a la reforma del artículo $8^{\circ}$ deberá interpretar dicha regla en clave de "afectación" de la seguridad de la Nación. Esto condiciona el enunciado del artículo 436 CJM, al exigir que la "relación directa" con la seguridad del Estado, deba ser leída y aplicada como una "afectación" o daño del bien jurídico protegido. Recientemente, en "Weatherhaven Chile S.A. con Estado Mayor Conjunto", el Consejo precisa que "[e]sta es la forma, a juicio de este Consejo, en que la aludida disposición del

${ }^{52}$ CpIT C512-09, cit. n. 50, cons. $5^{\circ}$.

${ }^{53}$ CpIT C512-09, cit. n. 50, cons. $7^{\circ}$.

${ }^{54}$ CplT C512-09, cit. n. 50, cons. $8^{\circ}-9^{\circ}$.

${ }^{55}$ CplT C512-09, cit. n. 50, cons. $10^{\circ}$.

${ }^{56}$ CplT C512-09, cit. n. 50, cons. $12^{\circ}$. 
Código de Justicia Militar debe ser interpretada para obtener un resultado que sea conforme con lo dispuesto por los artículos $21 \mathrm{~N}^{0} 5$ y primero transitorio de la Ley de Transparencia, así como con el texto vigente de la Constitución, habida consideración de que el artículo 436 del Código de Justicia Militar es una norma previa a la reforma del artículo $8^{\circ}$ de la Constitución" ${ }^{\prime 57}$. Finalmente, debe señalarse que la reconducción interpretativa exige una "afectación" en sentido abstracto. Es decir, se interpreta la regla legal de manera que no sea incompatible con la Constitución, pero el análisis concreto del caso y de la procedencia de la causal se reserva al juicio que se efectúa en el test de daño, como se analiza más abajo.

Es posible verificar la recepción de esta exigencia interpretativa en la sentencia de la Corte de Apelaciones de Santiago que rechazó el reclamo de ilegalidad deducido por el Ejército de Chile en contra de la citada decisión "Narváez Almendra con Ejército de Chile" ${ }^{\prime \prime 8}$. En ella, la respectiva sala consideró que las excepciones invocadas "[...] exigen, además de declaración de reserva o secreto mediante ley de quórum calificado, la afectación de la seguridad de la Nación o del interés nacional" ${ }^{59}$. Por lo tanto, si bien "[...] resulta ser efectivo que las normas [del artículo 436 CJM] del Código de Justicia Militar constituyen ley de quórum calificado, y que los capellanes y pastores que ejercen funciones en las Fuerzas Armadas forman parte de la dotación institucional [...] tales circunstancias no logran configurar, por sí solas, una excepción al acceso a la información que ha requerido el señor Narváez Almendras y que le ha reconocido el Consejo para la Transparencia [...]. En efecto, para configurar dicha excepción ha de estar, además, afectada la seguridad de la Nación o el interés nacional, y respecto de esta materia no existen antecedentes de que ello pueda razonablemente producirse de proporcionarse la información solicitada"60.

\section{Tercer presupuesto:}

\section{Subsunción de la información en la causal de reserva}

El tercer presupuesto corresponde a la subsunción de la información denegada en la causal de reserva o secreto establecida en la ley (válida). Se trata de un proceso de interpretación de la ley que primero efectúa la Administración y, eventualmente, es controlada por el CplT y por las Cortes de Apelaciones. No basta, aunque sea básico señalarlo, alegar una regla legal de reserva o secreto

\footnotetext{
${ }^{57}$ CplT C349-11 y C536-11 (acumuladas), cit. № 38, cons. $10^{\circ}$.

${ }^{58}$ Corte de Apelaciones de Santiago, Sentencia Rol № 2275-2010, de 23 de noviembre de 2010.

${ }^{59}$ Id., cons. $6^{\circ}$.

${ }^{60} I d$., cons. $7^{\circ}$.
} 
sino que ésta debe aplicarse, en el caso concreto, a la información que se está solicitando. En otros términos, debe verificarse que se cumpla la tipicidad legal de la reserva o secreto de la información.

La subsunción, como presupuesto de aplicación de la reserva o secreto, surge claramente reflejada en una de las decisiones del CpIT, cuando se aborda lo que debe entenderse por "pertrechos" militares o policiales ${ }^{61}$. En "Serani Mostazal con Carabineros", el Consejo debía decidir sobre una denegación de información en materia de contratos de telefonía celular entre una empresa y Carabineros de Chile, entre otras cuestiones ${ }^{62}$. El servicio, entre sus argumentos, sostuvo que la información debía ser calificada como reservada o secreta en virtud de lo dispuesto en el artículo $436 \mathrm{~N}^{\circ}$ 4, en lo referido a "equipos y pertrechos militares o policiales" como los "instrumentos necesarios para cualquier operación"63. El CplT estimó que "cabría determinar si nos encontramos frente a alguna [sic] de los actos o documentos calificados como 'equipos y pertrechos militares o policiales', o bien si la reserva de información solicitada viene dada por otra norma legal que establece una causal de reserva" ${ }^{\prime 64}$. En otros términos, el Consejo debía interpretar qué se entendía por "equipos" o "pertrechos", primero, y luego determinar si cabía su subsunción en la regla legal de reserva o secreto aducida por la Administración. Para afinar el análisis, el CplT afirma

"Que, al respecto, la vigésima segunda edición del Diccionario de la Lengua Española, de la Real Academia Española, contempla dos acepciones del término "pertrechos", primero como "Municiones, armas y demás instrumentos, máquinas, etc., necesarios para el uso de los soldados y defensa de las fortificaciones o de lo buques de guerra", y segundo como "Instrumentos necesarios para cualquier operación". En ninguna de sus dos acepciones es posible advertir a este Consejo de qué modo el contrato de provisión de servicios de telecomunicaciones suscrito entre el organismo reclamado y ENTEL pudiera ser calificado como "pertrechos militares o policiales", particularmente considerando la amplitud del segundo de los significados indicados, ni que su publicación afecte algunos de los bienes jurídicos del artículo $8^{\circ}$ de la Constitución, de modo que se descartará la aplicación de la norma del artículo 436 del Código de Justicia Militar como causal de reserva que permita fundar la denegación de dicha información. [...]"65.

Este considerando fusiona dos cuestiones que jurídicamente deben ser separadas, al menos para efectos de análisis. Una cosa es si los contratos de telefonía

${ }^{61}$ CplT C453-10, 26 de noviembre de 2010, "Serani Mostazal con Carabineros de Chile".

${ }^{62}$ CpIT C453-10, cit. n. 61, cons. $2^{\circ}$.

${ }^{63}$ CplT C453-10, cit. n. 61, cons. $2^{\circ}$.

${ }^{64}$ CplT C453-10, cit. n. 61, cons. $9^{\circ}$ (énfasis en el original).

${ }^{65}$ CplT C453-10, cit. n. 61, cons. $9^{\circ}$ (énfasis en el original). 
pueden ser subsumidos dentro de la expresión "equipos y pertrechos militares o policiales". Este es un primer paso interpretativo que debe resolverse para verificar la procedencia de aplicación de la regla de secreto. Otra cosa diferente es determinar, en el evento que se considere dichos contratos como "equipos" o "pertrechos", si su divulgación afecta la seguridad de la Nación. En nuestro esquema, una vez determinada la regla (válida) de reserva o secreto, debe interpretarse si el supuesto de hecho es subsumible en dicha regla. El análisis de afectación corresponde a un presupuesto distinto: la aplicación del test de daño.

La relevancia de separar los presupuestos radica en su utilidad y previsibilidad para efectos de la aplicación de las reglas de reserva o secreto. En el caso en comento, si el objeto materia de solicitud de información pública no es subsumible en la regla de reserva o secreto, entonces no procede efectuar el test de daño. Simplemente, no es aplicable al supuesto de hecho la regla que el servicio ha invocado para denegar la publicidad de la información. No es un problema de si su divulgación afecta o no la seguridad de la Nación -eventualmente podría generar tales efectos-; el problema es que la Administración carece de una regla aplicable (o al menos la invoca equivocadamente). Respecto de la aplicación del artículo 436 CJM, la regla tiene un ámbito semántico más preciso y definido y, a la vez, más limitado. Por ello, individualiza con mejor precisión la información que puede ser calificada de secreta aunque, simultáneamente y en razón de su precisión, deja fuera otras materias. El servicio al menos debe argumentar por qué la prestación de servicios de telefonía y ciertas cláusulas del contrato pueden ser considerados "documentos secretos" en lo relativo a "equipos y pertrechos militares o policiales". No hay que hacer un ejercicio lingüístico muy profundo para entender que servicios de telefonía y teléfonos - u otros equipos- no son términos idénticos ${ }^{66}$. Algunas reglas de reserva o secreto pueden ser amplias pero no abarcan todo. La Administración debe ser cuidadosa cuando intente denegar información en supuestos de hecho que no son subsumibles en la tipicidad de la regla. En este caso, el CpIT rechaza la aplicación de la regla de secreto porque no es subsumible a la información declarada secreta.

Una vez que el Consejo ha controlado que (1) la solicitud se ajusta al contenido protegido por el DAIP, (2) que existe una regla válida aplicable y (3) el

\footnotetext{
${ }^{66}$ Esta constatación, no obstante, no impide que el servicio argumente que los documentos, al estar "referidos" a servicios de telefonía que se ejecutan a través de "equipos y pertrechos militares o policiales", deban ser considerados secretos. Esto requiere que la Administración refine mínimamente sus argumentos y no asuma automáticamente que todo lo que se relacione o se "refiera" a determinados equipos y pertrechos militares o policiales es, por ello, subsumible en la causal de reserva o secreto del artículo 436 № 4 CJM. Otra estrategia argumentativa demandaría evitar la aplicación del artículo $436 \mathrm{~N}^{\circ} 4$ CJM y ampararse en las reglas más generales de reserva o secreto, como es el artículo 21 № 3 LT. Ello permitiría subsumir el supuesto de hecho en la regla, pero demandaría mayor densidad justificatoria en el tercer presupuesto: el test de daño.
} 
supuesto de hecho es subsumible en dicha regla, entonces pasa a controlar si la (4) divulgación de la información afecta la seguridad de la Nación.

\section{Cuarto presupuesto: Test de daño}

El último presupuesto en la determinación de la procedencia de una causal de reserva o secreto corresponde al denominado test de daño. La determinación de la afectación de la seguridad de la Nación se efectúa mediante la aplicación de un test de daño. Dicho test es el estándar que se ha construido por la dogmática comparada y ha sido asumido explícitamente por la temprana jurisprudencia del $\mathrm{CplT}^{67}$.

El Consejo ha definido el test de daño como el "balance entre el interés de retener la información y el interés de divulgarla para determinar si el beneficio público resultante de conocer la información solicitada es mayor que el daño que podría causar su revelación" ${ }^{\prime \prime 8}$. De acuerdo a la jurisprudencia del CpIT, el test de daño se deriva del reconocimiento del estatus iusfundamental del DAIP y que su limitación a través de la reserva o secreto "debe respetar el principio de proporcionalidad que supone analizar, conforme señala la doctrina: a) si la medida es eficaz, b) si no existe un medio más moderado para la consecución eficaz del propósito buscado (en este caso, cautelar el secreto) y, por último, c) si de la medida a adoptar (en este caso, el secreto absoluto) derivan más beneficios o ventajas para el interés general que perjuicios sobre otros bienes o valores en conflicto" ${ }^{\prime \prime 9}$. La referencia al principio de proporcionalidad, como concepto abarcador de los test de interés público y de daño, parece haber decrecido en decisiones posteriores.

El test opera como un presupuesto de corrección normativa de la decisión de declarar reservada o secreta cierta información. La aplicación del test de

\footnotetext{
${ }^{67}$ Uno de los trabajos más importantes en la materia -y que es citado por el CplT- es el de LópezAylzón, Sergio y Posadas, Alejandro, "Las pruebas de Daño e Interés Público en Materia de Acceso a la Información. Una Perspectiva Comparada", Derecho Comparado de la Información, enero-junio, 2007, pp. 21-65. En nuestro país, véase Tello, Cerna \& PAVÓn, "Acceso", cit. n. 2, pp. 198 y ss.; SÁnChez, Moisés, "Nueva Institucionalidad de Acceso a la Información Pública en Chile: Comentarios Legales", en VVAA, Hacia una Nueva Institucionalidad de Acceso a la Información Pública en Chile, Fundación ProAcceso, Santiago, 2008, p. 23. Tratando en detalle el test de daño en cuanto a sus componentes, criterios y método de aplicación, véase ConTRERAS, "Ponderación", cit. n. 10, passim.

${ }^{68}$ CplT A45-09, cit. n. 37, cons. $8^{\circ}$. El considerando continúa la definición respalda por los trabajos de López-Ayllón y Posadas, "Las pruebas de Daño", cit. n. 67, p. 23 y Tello, Cerna \& Pavón, "Acceso", cit. n. 2, pp. 198-9.

${ }^{69}$ CpIT A45-09, cit. n. 37, cons. $10^{\circ}$. El considerando respalda tal inferencia por dos vías: jurisprudencial, al citar a la Corte IDH Claude Reyes et al. v. Chile, cit. n. 7; y doctrinal, citando los trabajos de Bernal Pulido, Carlos, El Principio de Proporcionalidad y los Derechos Fundamentales, CEPC, Madrid, $2^{a}$ ed., 2008 y de García y Contreras, "Derecho de Acceso", cit. n. 2, pp. 144.
} 
daño en casos concretos varía y se verá en detalle en la relación de casos que presentamos más abajo ${ }^{70}$. Desde el punto de vista de la creación y desarrollo del presupuesto, el CplT ha ido refinando los componentes del test de daño en los casos relacionados con la afectación de la seguridad de la Nación. Así, ha empleado el test de daño como un requisito que articula la interpretación conforme a la Constitución de las leyes dictadas con anterioridad a la reforma del artículo $8^{\circ}$, como veíamos a propósito del segundo presupuesto ${ }^{71}$. De esta forma, preceptos legales como el artículo 436 del CJM -que utilizan el vocablo "relacionar" para conectar la información reservada con la causal de reserva de seguridad de la Nación- deben ser interpretados de manera tal que la divulgación de la información produzca al menos la "afectación" de dicho bien constitucional, tal como lo prescribe el artículo $8^{\circ}$ de la Carta Fundamental, en orden a autorizar el secreto de la misma ${ }^{72}$. Sin embargo, los dos presupuestos que aquí proponemos -reserva de ley de quórum calificado y test de dañopueden ser delimitados conceptualmente recurriendo a las nociones de daño y afectación "en concreto" o "en abstracto". El CplT, cuando establece la exigencia interpretativa de reconducción material al artículo $8^{\circ}$ de la Constitución-como veíamos a propósito del segundo presupuesto-, lo que hace es demandar una interpretación en razón de un daño abstracto, en la lectura de la regla en sí. En cambio, en el cuarto presupuesto -el test de daño-, el CpIT realiza un examen de afectación "en concreto", es decir, si en el caso puntual la información afectaría el bien jurídico protegido por la causal de reserva.

Al tratarse de un presupuesto que determinar la corrección normativa de la decisión de un servicio público en la restricción de un derecho fundamental, el CpIT ha comenzado a dotar de contenido a la cláusula de "seguridad de la Nación", para efectos de la aplicación del test de daño y para la evaluación de las declaraciones de reserva o secreto de información. Con tal objeto, el Consejo ha optado por un concepto "reducido" de seguridad de la Nación acotándolo a un "contenido más cierto", cual es la protección de "la fortaleza bélica y las relaciones exteriores necesarias para que no se amenace la integridad territorial"n3.

\footnotetext{
${ }^{70}$ Véase infra IV.

${ }^{71}$ Véase supra III.2.

${ }^{72}$ CpIT C512-09, cit. n. 50, cons. 12.

${ }^{73}$ CplT C652-10, cit. n. 20, cons. 16 (énfasis en el original). El Consejo ha hecho suya la definición de CORREA SUTIL, Jorge, La Seguridad de la Nación y el Interés Nacional como Límite a la Publicidad de Ios Actos y Resoluciones de los Órganos del Estado, Santiago, Informe en Derecho requerido por el Consejo para la Transparencia, Inédito, 2009 (copia en poder de los autores), p. 76. El trabajo de Correa sigue de cerca la regulación del DAIP en Estados Unidos ("freedom of information", bajo la "Freedom of Information Act"). El Consejo debiese ser cuidadoso al adoptar esta regulación comparada como
} 
Una vez restringido el concepto de seguridad de la Nación, el CplT reitera los elementos aplicables al test de daño:

P]ara determinar la afectación a los bienes jurídicos protegidos por las causales de reserva o secreto de la información, es necesario, en primer lugar, no sólo que la información de que se trate concierna a la materias sobre las que éstos versan, sino que además debe dañarlos o afectarlos negativamente en alguna magnitud y con alguna especificidad que habrá de ser determinada, daño que no cabe presumir, sino que debe ser acreditado por los órganos administrativos que tiene alguna probabilidad de ocurrir y, en segundo lugar, debe existir proporcionalidad entre los daños que la publicidad provoca a alguno de los bienes establecidos en Ley de Transparencia y el perjuicio que el secreto causa al libre acceso a la información y al principio de publicidad (decisiones Roles A1-09, de 23 de junio de 2009, A3909, de 19 de junio de 2009, y A45-09, de 28 de julio de 2009 y C669-10, de 2 de noviembre de 2010)"174.

Este considerando resume los elementos y la operatividad del test. La exigencia de probabilidad de ocurrencia del daño será definida, posteriormente, como una "expectativa razonable de afectación de la defensa nacional en caso de revelarse la información solicitada $[\ldots]^{\prime \prime 75}$. El examen de proporcionalidad, por otro lado, ha sido casuístico y detallamos ejemplos de su aplicación en la parte de revisión de los casos.

El test de daño, como último presupuesto empleado para la determinación de una causal de reserva o secreto, se encuentra actualmente bien asentado en la jurisprudencia del Consejo ${ }^{76}$. Esto, sin embargo, no resta de problemas

ejemplo de respaldo para su definición restrictiva de seguridad de la Nación. El problema radica en la regulación interna de las causales de reserva en el derecho estadounidense. Tal como se describe en el Informe en Derecho de Correa y se reproduce en el considerando citado, esta regulación se efectúa por medio de "Executive Orders", es decir, actos reglamentarios emanados del Poder Ejecutivo y no a través de la ley, como exige la Corte Interamericana de Derechos Humanos y nuestra Constitución. En consecuencia, el Presidente de los Estados Unidos puede alterar sustantivamente los alcances de las causales de reserva relacionadas con la seguridad de la Nación, especialmente, en materias de terrorismo. En tal sentido, es razonable tener presente que tal regulación ad hoc puede no ser del todo coincidente con el concepto de seguridad de la Nación del artículo $8^{\circ}$ de la Constitución. En este sentido, la seguridad de la Nación en Estados Unidos podría agregar materias de orden interno que no dicen relación con la defensa de la soberanía nacional ni con la integridad territorial de Chile. Sobre los problemas que la "Guerra contra el Terrorismo" ha generado en materia de DAIP en Estados Unidos, véase SunsteIn, Cass R., "National Security, Liberty, and the D.C. Circuit", George Washington Law Review, Vol. 73, pp. 693-708, esp. pp. 697-700.

${ }^{74}$ CpIT C652-10, cit. n. 20, cons. $17^{\circ}$.

${ }^{75}$ CpIT C159-11, 10 de mayo de 2011, "Sagredo Stevens con Dirección General de Aeronáutica Civil", cons. $9^{\circ}$.

${ }^{76}$ En posible identificar cierta recepción del denominado test de daño en la Corte de Apelaciones de Santiago en sentencia Rol № 806-2011, de 31 de mayo de 2011, caratulada "Dirección del Trabajo 
en su definición y aplicación para los casos concretos. Desde el punto de vista conceptual -y sólo para efectos del análisis- destacaremos dos problemas que surgen en la definición y empleo del test de daño como presupuesto general.

El primero de los problemas conceptuales dice relación por el "acoplamiento" del test de daño con la exigencia de interpretación de leyes previas a la reforma al artículo $8^{\circ}$ conforme al criterio de "afectación". El tratamiento jurisprudencial del Consejo, en este punto, parece mezclar, por un lado, la determinación de la norma válida que autoriza el secreto, con la exigencia de afectación misma de la seguridad de la Nación, por el otro. En este sentido, sería conveniente separar el deber de interpretación conforme a la Constitución de las leyes pre-2005 del examen mismo de afectación o daño. De lo contrario, se superponen dos presupuestos que conceptualmente deben tratarse de manera diferenciada.

El segundo problema es también de índole conceptual, aunque parece estar conectado a un uso inapropiado de la terminología del test de daño y del test de interés público. El test de interés público ha sido definido por la doctrina como la ponderación entre el "interés de protección de la privacidad" entendido como "el control que un individuo tiene o debe tener sobre la información concerniente a su persona", por un lado, y el interés de publicidad y de transparencia protegido por las leyes de acceso a la información pública ${ }^{77}$. El CpIT emplea el nombre del test como términos intercambiables o sinónimos. En el Derecho comparado, el test de daño ha sido adoptado a efectos de verificar la "afectación" de bienes colectivos de carácter constitucional que, en cuanto objetos de protección, han sido recogidos en las causales de secreto o reserva, mientras el test de interés público protege los derechos de terceros ${ }^{78}$.

El Consejo deberá hacer un esfuerzo para clarificar el alcance conceptual de ambos test y su objeto de protección. Hasta el momento, parece entender

con Consejo para la Transparencia". En ella concluye que "por no advertirse en la especie la existencia ni el peligro de lesión o daño concreto en desmedro de las garantías constitucionales y legales de los suscriptores intervinientes ni de la Dirección del Trabajo recurrente, estos sentenciadores no divisan motivo legal que justifique la prohibición de entrega de los instrumentos en cuestión" (cons. $6^{\circ}$ ) (el destacado es nuestro).

77 López-Ayllón y Posadas, "Las pruebas de Daño", cit. n. 67, p. 37.

${ }^{78}$ RAJEVIC, "La Jurisprudencia Inicial", cit. n. 2, p. 45. Los siguientes son ejemplos ilustrativos del uso del test de interés público frente al régimen de protección de datos personales: CpIT C193-10, de 15 de julio de 2010, "Alcayaga Olivares con Superintendencia de Seguridad Social"; CplT C315-11, de 10 de mayo de 2011, "Contreras Concha con Ministerio de Vivienda y Urbanismo"; y CplT C111-11, de 7 de junio de 2011, "Ossandón Díaz con Universidad de Valparaíso". En doctrina, también véase RAJEVIC, Enrique, "Protección de datos y transparencia en la administración pública chilena: Inevitable y deseable ponderación", en VVAA, Reflexiones sobre el Uso y Abuso de los Datos Personales en Chile, Expansiva, Santiago, 2011. Una sistematización de las decisiones del CpIT en materia de datos personales en Consejo para la Transparencia, Protección de datos personales, Santiago, 2011. 
que ambos test son expresión del principio de proporcionalidad en el control de las restricciones de derechos fundamentales ${ }^{79}$. Sin embargo, si así fuere, no se entiende bien el empleo de nomenclaturas diferenciadas si el control de la argumentación de la administración es funcionalmente equivalente en casos de seguridad de la Nación versus los de derechos de terceros. Al ser test distintos con presupuestos diferenciables, sería razonable seguir la distinción que ha desarrollado el Derecho comparado.

\section{Clasificación de la jurisprudencia del Consejo para la Transparencia}

Esta sección detalla grupos de casos en los que el Consejo ha empleado los presupuestos generales que hemos detallado. Esta sistematización permite contrastar la aplicación de los criterios jurisprudenciales y dar cuenta del estado de la cuestión en materia de acceso a la información pública y resguardo de la seguridad de la nación.

\section{Información inexistente y expurgada}

La regulación sobre archivo y eliminación de documentos en la Administración del Estado ha dejado a la discrecionalidad de las instituciones del ámbito de la defensa nacional la conservación de los documentos relativos a ellas. Parte de esto lo revisamos a propósito del primer presupuesto aplicable en materia de seguridad de la Nación y en el contexto normativo allí descrito, no es de extrañar que sea con ocasión de una decisión sobre acceso a información en poder de las FF.AA. -"Pérez Viveros con Fuerza Aérea de Chile" ${ }^{80}$ - que encontremos una sistematización de ciertos estándares para la plausibilidad de la inexistencia como fundamento para la denegación de información.

El primero de estos estándares supone que "al alegarse que la información solicitada no existe o no obra en su poder, deberá verificarse si conforme al ordenamiento jurídico el organismo requerido es competente para conocer de la solicitud o se encuentra obligado a poseer dicha información. En caso negativo [...] se entenderá que el organismo ha dado cumplimiento a la obligación de dar respuesta a la solicitud de información, cuando indique al requirente los fundamentos por los que la información solicitada no existe o no obra en su poder" ${ }^{\prime \prime 1}$.

\footnotetext{
${ }^{79}$ RAJEVIC, "La Jurisprudencia Inicial", cit. n. 2, p. 46, citando CpIT A45-09, cit. n. 37, cons. $10^{\circ}$.

${ }^{80}$ CpIT C804-10, cit. n. 24. En ella correspondió al CpIT pronunciarse sobre el acceso a las resoluciones de baja de dos aeronaves de la Fuerza Aérea de Chile en la década de los $70^{\prime}$ y un mensaje encriptado de la misma época, los que no habían sido hallados al revisarse la solicitud de información.

${ }^{81}$ CplT C804-10, cit. n. 24, cons. $4^{\circ}$.
} 
Un ejemplo en ese sentido se constata en "Skoknic Galdames con Ejército de Chile" ${ }^{\prime 2}$, relativa al acceso a los contratos para proveer sistemas de armas, piezas y repuestos para material de guerra supuestamente suscritos entre el Ejército de Chile y la empresa Servicios Logísticos Ltda. En ella se acoge la inexistencia de dichos contratos tras constatar que "dicha empresa sólo habría actuado como agente comercial teniendo un rol de intervención, participación o vinculación en los procesos de adquisición [...] pero no habría suscrito contratos de aquellos solicitados por la reclamante, por lo que no sería una proveedora del Ejército de Chile $^{\prime 83}$. Sin embargo, para arribar a tal aserto, el Consejo requirió al Ejército, como medida para mejor resolver, especificar el rol que tuvo la empresa en los procedimientos de adquisición llevados a cabo ${ }^{84}$.

En segundo lugar, el Consejo ha entendido que en aquellos casos en que el organismo requerido fuese competente para conocer de la solicitud o se encuentre obligado a poseer la información requerida, para fundar plausiblemente su inexistencia, éste deberá "probar que dispuso la expurgación de los documentos solicitados". Ello deberá realizarlo, en general, "acompañando el acto administrativo que lo ordenó y el acta respectiva, en los términos señalados por la Circular № 28.704, de 1981, de la Contraloría General de la República"85. Sin embargo, respecto de los organismo de la defensa nacional a que se refiere el artículo 14, inciso final, del D.F.L. $N^{0}$ 5.200, para el cumplimiento de tal estándar, deberá verificarse en la normativa sectorial pertinente el mecanismo de archivo y destrucción contemplado por ellas, exigiéndose la presentación de la resolución o acta de destrucción respectiva, según sus normas especiales. En efecto, en "Pérez Viveros con Fuerza Aérea de Chile", el CplT observó la normas especiales de esta institución, conforme a las cuales "[t]oda la documentación no seleccionada para el archivo histórico será destruida elaborándose el acta correspondiente $[\ldots]$ " y dicha "[...] acta de destrucción deberá ser firmada por los encargados de la custodia [...]", debiendo mantenerse en el "archivo permanente" de la institución ${ }^{86}$.

\footnotetext{
${ }^{82}$ CpIT C382-11, cit. n. 25.

83 Ídem, cons. $1^{\circ}$.

${ }^{84}$ Ídem, № $5^{\circ}$ de la parte expositiva.

${ }^{85}$ CplT C804-10, cit. n. 24, cons. $5^{\circ}$.

${ }^{86}$ CpIT C804-10, cit. n. 24, cons. $8^{\circ}$. Al efecto, el CplT revisó los artículos 111, 117 y 119 del Reglamento Serie $\mathrm{D} \mathrm{N}^{\circ}$ 6, de Documentación de la Fuerza Aérea de Chile, aprobado por Resolución FACH (C.J.) № E-0127, de 21 de marzo de 2010. En similar sentido, véase CpIT A58-09, de 9 de septiembre de 2010, "Candel Pozo con Carabineros de Chile" (resolución de reposición), relativa a la aplicación del Reglamento de Documentación № 22 de Carabineros de Chile (D.S. № 3.612/1961, del Ministerio del Interior, actualizado por el D.S. № 481, de 1997, del Ministerio de Defensa Nacional) y su Directiva Complementaria, aprobada por Orden General № 1.255, de 2 de abril de 1998, de la Dirección General de Carabineros.
} 
Por último, y en forma excepcional, en aquellos casos en que el órgano no cuente con la resolución o acta que dé cuenta de su destrucción de la información -como ocurrió en el caso precitado-, el Consejo aceptará que ésta no obra en su poder, "previa búsqueda exhaustiva de los documentos", de lo que deberá dar cuenta mediante "acta de búsqueda" elaborada al efecto ${ }^{87}$.

\section{Información relacionada con las plantas y el personal de las Fuerzas Armadas y Carabineros de Chile}

Uno de los primeros casos del Consejo relativos con la seguridad de la Nación tuvo relación con materias de información sobre plantas y personal de las instituciones castrenses. Como vimos, en "De la Carrera Valdés con Carabineros de Chile" ${ }^{88}$, al Consejo le correspondió resolver si, de conformidad con el artículo $436 \mathrm{~N}^{\circ} 1$ del CJM, es secreto el número de carabineros destinados al Departamento de Protección de Personas Importantes de Carabineros de Chile (en adelante, DPPI) y el número de personas que reciben este tipo de protección. En tal caso, el CpIT concluyó que la revelación de su dotación "[...] produciría un daño o detrimento en el debido cumplimiento de las funciones de dicho departamento. En efecto, conocer esta información afectaría la planificación estratégica de dicho Departamento y, por tanto, su función principal, cual es proteger a dichas personas de eventuales atentados delictivos derivados de su autoridad o importancia. Conectada esta información con las personas protegidas se develaría su capacidad operativa efectiva, generando o una sensación de escasez de personal y desprotección o una de exceso de personal dedicado a estas tareas. Lo primero impulsaría la comisión de los atentados que se quiere evitar; lo segundo generaría un debate que impulsaría la necesidad de revelar más antecedentes -incluso la dotación de cada una de las Unidades o Departamentos de Carabineros- rigidizando y restando eficacia a la actividad policial, que pasaría a ser del todo previsible ${ }^{\prime 89}$. Consecuentemente -agregó el CplT- "de conocerse este dato y reducirse la eficacia del Departamento, conforme ya se explicó, se afectaría la seguridad pública [en los términos del artículo $\left.21 \mathrm{~N}^{\circ} 3 \mathrm{LT}\right]$ pues ésta se ve directamente impactada cuando una autoridad es víctima de un delito. Lo mismo puede decirse de la seguridad de las personas protegidas en virtud de este programa, afectadas en tanto éste perdería eficacia" ${ }^{\prime 90}$.

${ }^{87}$ CplT C804-10, cit. n. 24, cons. $9^{\circ}$.

${ }^{88}$ CplT A45-09, cit. n. 37.

${ }^{89}$ CplT A45-09, cit. n. 37 , cons. $12^{\circ}$.

${ }^{90}$ CpIT A45-09, cit. n. 37 , cons. $13^{\circ}$. 
En dicha decisión es posible identificar la utilización de algunos de los presupuestos que hemos venido desarrollando. En primer lugar, al revisar la aplicabilidad del artículo 436 del CJM el Consejo reconduce materialmente dicha disposición al artículo $8^{\circ}$ de la CPR ${ }^{91}$. Así las cosas, según el CpIT, la referencia al carácter secreto de los documentos "relacionados directamente" con la "seguridad de las personas" y el "orden público interior" de su encabezado, se identificaría, respectivamente, con el reguardo de la seguridad de la Nación y los derechos de las personas, pues así lo señalan expresamente los ejemplos que establecen los numerales 2 y 3 del artículo 21 de la LT (cons. $2^{\circ}$ a $5^{\circ}$ ). Tal conclusión validaría dichos casos de secreto pre-reforma constitucional 2005, así como los ejemplos a que se refiere su numeral primero, siempre y cuando en los hechos se verifique su afectación. En segundo lugar, si bien en sus consideraciones no se subsume explícitamente la información en el numeral $1^{\circ}$ del artículo $436 \mathrm{CJM}$, de su tenor se verifica que el Consejo asimila directamente lo pedido con la revelación de la "dotación" de un departamento de Carabineros de Chile -aunque no aborda el sentido o alcance de dicho término- ${ }^{92}$. Por último, esta decisión constituye un primer intento por desarrollar el test de daño ${ }^{93}$ como una proyección de la cadena de consecuencias que la comunicación de la información implica para los intereses protegidos por más de una causal de reserva, a saber: la comunicación de la dotación devela la capacidad operativa del DPPI, ergo, (a) su conocimiento generará una sensación de escasez de personal, incrementando la posibilidad de atentados; o (b) creará una sensación de exceso de personal, lo que obligaría a develar mayores antecedentes, tornando previsible el actuar policial, restándole eficacia $^{94}$.

Cabe destacar que el voto disidente del Consejero Olmedo en la decisión en comento incorpora una primera referencia a los estándares de argumentación y prueba que importaría el test de daño. A su entender, mediante este test se "debe acreditar que la afectación a la o las causales constitucionales de secreto o reserva debe ser cierto, probable y específico, condiciones que no se reúnen en este caso ${ }^{\prime \prime 95}$. Sin embargo, el voto disidente no avanza en desarrollar qué deberá entenderse por cada uno de dichos estándares. Como contrapunto, resulta llamativa la invocación en la argumentación de mayoría de los resultados del test de interés público en esta decisión, en orden a que la comunicación

\footnotetext{
${ }^{91}$ Véase supra III.2.

${ }^{92}$ CplT A45-09, cit. n. 37, cons. $2^{\circ}$.

${ }_{93}$ Véase supra III.4.

${ }^{94}$ CplT A45-09, cit. n. 37 , cons. $12^{\circ}$ y $13^{\circ}$.

${ }^{95}$ CplT A45-09, cit. n. 37, voto disidente, cons. $4^{\circ}$ (énfasis agregado).
} 
de estos antecedentes generaría un "daño superior al beneficio que la divulgación de esta información aportaría al debate público y al control social de la acción policial"96, pues el Consejo no desarrolla mayormente los argumentos que justifican este beneficio.

Otro caso relevante es "Fuentes Castro con Gendarmería de Chile"97. En él, el CpIT debió resolver, entre otras materia, el acceso a la identidad, funciones y remuneraciones del personal de Gendarmería (a contrata y honorarios) que se desempeña en el Centro Penitenciario Punta Peuco. Dicha información fue considerada secreta, en base a la concurrencia de dos causales de secreto. En primer lugar, porque su comunicación "[...] expondría a los gendarmes del recinto $-y$ a los propios internos- a probables situaciones de peligro, pues implicaría revelar las debilidades que hubiesen y generaría las consiguientes vulnerabilidades, afectando con ello el debido cumplimiento de sus funciones, cual es atender, custodiar y asistir a las personas detenidas, sujetas a prisión preventiva y condenadas en dicho recinto" ${ }^{\prime 98}$. Consecuentemente, "lo anterior afectaría la seguridad pública"99, a la que se refiere el artículo 21 № 3 LT como ejemplo de afectación a la seguridad de la Nación. En segundo término, el Consejo estimó que la comunicación de esta información "[...] representa un daño presente, probable y específico al orden y seguridad internas del recinto, subsumible en la causal de reserva contemplada en el artículo $21 \mathrm{~N}^{\circ} 1$ de la Ley de Transparencia toda vez que, según lo dispuesto en el artículo $3^{\circ}$ a) del D.L. № 2.859/1979, que aprueba la Ley Orgánica de Gendarmería de Chile, corresponde a este servicio velar por la seguridad interior de los establecimientos penales del país"100. Si bien esta representa una primera referencia a estándares probatorios sobre el daño a los intereses jurídicamente protegidos por la reserva, particularmente de la seguridad pública como consecuencia de la afectación el debido cumplimiento de funciones de un servicio, ella no desarrolla mayormente sus componentes.

Posteriormente, en "Narváez Almendra con Ejército de Chile"101, el Consejo debió resolver si es secreto la individualización de los capellanes o asesores espirituales que forman parte del Ejército de Chile -ya sea como parte de su planta, contrata o personal a honorarios-, el lugar donde se desempeñan, su antigüedad y remuneraciones, a la luz del artículo 436, № 1 CJM. Si bien re-

\footnotetext{
${ }^{96}$ CpIT A45-09, cit. n. 37, cons. $13^{\circ}$.

${ }^{97}$ CplT A193-09, de 3 de marzo de 2009, "Fuentes Castro con Gendarmería de Chile".

${ }_{98}^{9}$ CpIT A193-09, cit. n 97, cons. $9^{\circ}$.

${ }^{99}$ CplT A193-09, cit. n 97, cons. $9^{\circ}$.

${ }^{100}$ CpIT A193-09, cit. n 97, cons. $10^{\circ}$ (énfasis agregado).

${ }^{101}$ CplT C512-09, cit. n. 50.
} 
sultaba claro que la información se "relaciona directamente" con la Defensa Nacional por tratarse de "documentos relativos" a la planta o personal del Ejercito de Chile ${ }^{102}$, tras profundizar en la interpretación de dicha disposición conforme con la Constitución, el Consejo se concentra en determinar si en las circunstancias del caso concreto se verifica un daño a los intereses protegidos por la causal de reserva, descartando tal escenario. En efecto, advierte que, por un lado, información de naturaleza similar se encuentra divulgada: la nómina de capellanes contratados a honorario es publicada por el Ejército en su sitio electrónico y ella "contempla gran parte de la información requerida"103. Por otra parte, el organismo esgrimió razones discriminatorias para denegar el acceso a la información, a saber, la condición de periodista del requirente, lo que se encuentra vedado por el principio de no discriminación, consagrado en el artículo 11, letra g, de la $\mathrm{LT}^{104}$.

Otra particularidad a destacar es que el CpIT representa al Ejército de Chile no remitirle, como medida para mejor resolver, la información objeto de la reclamación de amparo, como expresamente le fuera solicitado invocando los artículos 26 y $34 \mathrm{LT}$, advirtiéndole que esta medida "habría facilitado determinar si el contenido de dicha información avalaba los descargos presentados"105. Dicha petición había sido denegada expresamente por el Ejército, por considerar que la información sería secreta incluso respecto del Consejo. No obstante ello -señala el CplT- los demás antecedentes existentes fueron suficientes para que éste pudiese adoptar su decisión ${ }^{106}$.

\footnotetext{
${ }^{102}$ Así lo expuso el Ejército de Chile, haciendo presente lo dispuesto por el artículo $4^{\circ}$ de la Ley Orgánica Constitucional de las Fuerzas Armadas, № 18.948, de 1990, en relación con el artículo $2^{\circ}$ del D.F.L. $\mathrm{N}^{\circ}$ 1, de 1997, sobre el Estatuto del Personal de las Fuerzas Armadas ( $\mathrm{N}^{\circ}$ 2, letra e, parte expositiva de la decisión)

${ }^{103}$ CplT C512-09, cit. n. 50, cons. $14^{\circ}$.

${ }^{104}$ CpIT C512-09, cit. n. 50, cons. $16^{\circ}$.

${ }^{105}$ CplT C512-11, cit. n. 50, cons. 15.

${ }^{106}$ CpIT C512-11, cit. n. 50, cons. 15. En su decisión CpIT C406-11, de 12 de agosto de 2011, "Alcalde Municipalidad de Melipilla con Subsecretaría del Interior", relativa a la denegación de acceso a determinados mensajes remitidos por correo electrónico desde las casillas institucionales de algunos de sus funcionarios, el CpIT se pronunció sobre los fundamentados de sus facultades para conocer el contenido de la información objeto de controversia, previo a resolver el asunto. Al efecto, argumentó que "[l]a interpretación del artículo 34 de la Ley de Transparencia que realizó el Tribunal Constitucional respecto de la facultad del Consejo para 'recibir todos los testimonios y obtener todas las informaciones y documentos necesarios para el examen de las situaciones comprendidas en el ámbito de su competencia' [según la cual, esta disposición es constitucional en tanto el ejercicio de dicha potestad reconoce como límite las excepciones a la publicidad de los actos y resoluciones de los órganos del Estado], es entendida [...] como un recordatorio de la necesidad de mantener una reserva preventiva respecto de los antecedentes que reciba en aplicación del artículo 26, en otras palabras, debe armonizarse con las disposiciones plenamente vigentes de los artículos 25, 26 y 33, letras b)
} 
Una particularidad a destacar en este caso es la votación disidente del entonces Presidente del Consejo, quien estuvo por declarar secreta la información, cuestionando la interpretación conforme con la Constitución desarrollada por la mayoría. Al efecto, sostuvo que "en cuanto a los capellanes [...] sean funcionarios de planta o a contrata del Ejército de Chile[,] este Consejo debe respetar las normas legales vigentes, en este caso[,] el artículo 436 del Código de Justicia Militar que establece su secreto o reserva sin mayores distinciones y sin efectuar una especie de análisis de constitucionalidad de su contenido"107. A la larga, la argumentación de mayoría sería ratificada por la Corte de Apelaciones de Santiago al conocer del reclamo de ilegalidad deducido por el Ejército de Chile. En dicha sede, junto con validar la argumentación del Consejo acerca de la reconducción material de las causales de secreto pre-reforma constitución de 2005 -en particular del artículo 436 CJM-108, demostró la convicción de la Corte acerca de la necesidad de ciertos estándares probatorio sobre los antecedentes del caso concreto. En efecto, la sala respectiva rechazó las alegaciones de hecho del organismo, por estimarlas infundadas, toda vez que: "[l]as afirmaciones del reclamante de que los antecedentes denegados, en conocimiento de potenciales adversarios, les permitiría diseñar estrategias defensivas u ofensivas que dañen gravemente al país, a sus intereses y a su población, por no estar respaldadas en antecedentes concretos, constituyen sólo apreciaciones personales y subjetivas"109.

La aplicabilidad del art. 436 CJM como hipótesis de reserva de la identidad de oficiales de las FF.AA. también fue objeto de estudio en "Lux Palma con Armada de Chile"110, donde el CpIT resolvió la publicidad de la identidad del oficial a cargo de la selección de los tripulantes de uno de sus buques y de quien dio las instrucciones relativas al procedimiento de selección de pasajeros, en el contexto del terremoto de 27 de febrero de 2010 -ocasión en la que se evacuó a familiares del personal de la Armada desde Talcahuano-. El Consejo, en forma unánime, concluyó que "[e]l hecho de que las personas cuya identidad se consulta formen parte de la planta de la Armada no supone, por ese solo hecho, que su identidad sea secreta o reservada, pues, a partir de la interpretación sostenida por este Consejo, el artículo 436 del CJM dispone el carácter secreto de documentos

y j), del mismo cuerpo legal, cuya constitucionalidad no ha sido discutida ni cuestionada por dicho Tribunal" (cons. 11\%). En igual sentido, véase CplT C690-11, de 6 de septiembre de 2011, "Vásquez con Consejo de Defensa del Estado".

${ }^{107}$ CplT C512-09, cit. n. 50, voto disidente, cons. $3^{\circ}$.

${ }^{108}$ Corte de Apelaciones de Santiago, Sentencia Rol No 2.275-2010, de 23 de noviembre de 2010, cons. $6^{\circ}$ y $7^{\circ}$. Véase supra III.2.

${ }^{109} \mathrm{Id}$., cons. $7^{\circ}$, parte final (énfasis agregado).

${ }^{110}$ CplT C652-10, cit. n. 20. 
relativos a las plantas o dotaciones de las Fuerzas Armadas o de Carabineros de Chile y de su personal, en tanto cuanto su divulgación afecte la seguridad de la Nación"111. Esta decisión conoce de especial trascendencia pues constituye una primera sistematización de los estándares probatorios a que deberá someterse la invocación de hipótesis de reserva -por el test de daño-, particularmente el $N^{\circ} 1$ del artículo $436 \mathrm{CJM}$. En efecto, adoptando algunas de las nociones que ha aportado la doctrina para la delimitación del contenido del concepto seguridad de la Nación ${ }^{112}$, el Consejo sostuvo que "[...] para determinar la afectación a los bienes jurídicos protegidos por las causales de reserva o secreto de la información, es necesario, en primer lugar, no sólo que la información de que se trate concierna a la materias sobre las que éstos versan, sino que además debe dañarlos o afectarlos negativamente en alguna magnitud y con alguna especificidad que habrá de ser determinada, daño que no cabe presumir, sino que debe ser acreditado por los órganos administrativos que tiene alguna probabilidad de ocurrir $[\ldots]^{\prime 113}$. Con todo, la decisión agrega que "[...] en segundo lugar, debe existir proporcionalidad entre los daños que la publicidad provoca a alguno de los bienes establecidos en Ley de Transparencia y el perjuicio que el secreto causa al libre acceso a la información y al principio de publicidad"114.

En conformidad con estos criterios, el CplT concluyó que la comunicación de lo solicitado no generaría el daño alegado, pues: (a) información de igual naturaleza ya era divulgada por el servicio [en su sitio electrónico comunicaba la identidad de los oficiales unidades de su estructura orgánica], por tanto "[e]ntender lo contrario supondría que la propia Armada incurriría en una violación a sus disposiciones de secreto"; (b) de conformidad con las reglas de la carga de la prueba no se habían "[...] formulado argumentos de hecho que, en este caso, permitan identificar las circunstancias de riesgo de daño a la seguridad de la Nación"; y, por último, (c) porque la reserva no era "un medio idóneo o adecuado para proteger la seguridad de la Nación", toda vez que revisado el sitio electrónico de la Armada se observó que ésta divulgaba la identidad de uno de los oficiales ${ }^{115}$.

Por último, la cuestión jurídica a resolver en "Balmaceda Hoyos con Armada de Chile" 116 fue la reserva de las listas de calificación del personal de la Armada, que definen el retiro de parte de la dotación institucional, por aplicación del

\footnotetext{
${ }^{111}$ CplT C652-10, cit. n. 20, cons. 18, a).

112 Véase supra III.4.

${ }^{113}$ CplT C652-10, cit. n. 20, cons. $17^{\circ}$ (énfasis agregado).

${ }^{114}$ CplT C652-10, cit. n. 20, cons. $17^{\circ}$ (énfasis agregado).

115 CpIT C652-10, cit. n. 20, cons. $18^{\circ}$ (énfasis agregado).

${ }^{116}$ CpIT C870-10, de 29 de noviembre de 2010, "Balmaceda Hoyos con Armada de Chile".
} 
artículo 436 № 1 CJM. En ella, tras confirmar el criterio de reconducción material a que arribó en Narváez Almendras con Ejército de Chile (cons. $7^{\circ}-11^{\circ}$ ), el Consejo resolvió el carácter público del "listado y número del personal incluido en Lista 4 [...] como también del clasificado por segunda vez consecutiva en Lista $3[. .$.$] pues conforme al artículo 76$ del Estatuto del Personal de las FF.AA. [dicho personal] deberá necesariamente ser eliminado del servicio [...]", razón por la cual éstos dejarían de integrar la dotación militar ${ }^{117}$. Por el contrario, estimó comprendidas en la hipótesis de reserva las Listas $N^{0} 1$ y Lista $N^{\circ} 2$, pues dicha información, "combinada con la información que se está entregando, permitiría averiguar la dotación de la Armada de Chile con gran certeza [,] vulnerando la reserva dispuesta en el artículo 436 ya citado"118.

\section{Información sobre las Juntas de Calificación}

En dos de sus decisiones el CpIT se ha pronunciado sobre publicidad de los antecedentes considerados por las Juntas de Selección de las FF.AA., al calificar a su personal y elaborar sus listas de retiro. Dichas funciones son encomendadas a las Juntas de Selección por el artículo 26 LOC FF.AA., según el cual "[l]as sesiones y actas de las Juntas serán secretas" (inciso $6^{\circ}$ ), y éstas "son soberanas en cuanto a las apreciaciones que emiten sobre la idoneidad, eficiencia profesional y condiciones personales de los calificados, no correspondiendo a otros organismos ajenos a las respectivas instituciones castrenses la revisión de los fundamentos de sus decisiones" (inciso $5^{\circ}$ ).

Tal como revisamos más arriba ${ }^{119}$, en aplicación de la citada norma de secreto, en "Díaz Acuña con Fuerza Aérea de Chile"120 el CplT denegó el acceso a "Ios fundamentos que Ilevaron a la Junta Especial de Selección [...] de la $\mathrm{FACH}$, a determinar la inclusión en la Lista de Retiros al reclamante"121, haciendo suyos los argumentos formulados la CGR a favor de la validez formal del citado artículo 26. Al efecto, concluyó que "se ha configurado fehacientemente la causal consagrada en el artículo $21 \mathrm{~N}^{\circ} 5$ de la Ley de Transparencia, no debiendo divulgarse la información individualizada, pues afectaría la seguridad de la Nación"122. Sin embargo, a diferencia de sus análisis del artículo 436 CJM, no es posible identificar en esta primera decisión una argumentación

\footnotetext{
${ }^{117}$ CplT C870-10, cit. n. 116, cons. 12, e).

${ }^{118}$ CplT C870-10, cit. n. 116, cons. 12, f).

119 Véase supra III.2.

${ }^{120}$ CplT A266-09, cit. n. 42.

${ }^{121}$ CplT A266-09, cit. n. 42, cons. $4^{\circ}$.

${ }^{122}$ CplT A266-09, cit. n. 42, cons. $9^{\circ}$.
} 
autónoma en orden a fundamentar la reconducción material de esta disposición de secreto a las causales constitucionales, ni alusiones a la aplicabilidad del test de daño en el caso concreto, lo que podría responder a la especificidad de la hipótesis de secreto del art. 26 LOC FF.AA., a diferencia de la tipicidad abierta del artículo 436 del CJM, ante la que el Consejo ya había fijado esta posición hermenéutica.

Con todo, contrariamente a dicha posición, la Corte de Apelaciones de Santiago, conociendo del reclamo de ilegalidad interpuesto en contra de la precitada decisión ${ }^{123}$, ratificó la necesidad de reconducir materialmente las hipótesis de secreto a la Constitución, señalando: "Que la norma constitucional exige, además, que la publicidad que puede restringir una ley de quórum calificado afecte el debido cumplimiento de las funciones de los órganos del Estado, los derechos de las personas, la seguridad de la Nación o el interés nacional"124. Así las cosas, estimó que es el carácter obediente, no deliberantes, profesional, jerarquizado y disciplinado de las FF.AA. -artículos 101 CPR y $2^{\circ}$ LOC FF.AA.-, lo que fundamenta que las Juntas de Selección del personal de cada institución sean soberanas en la apreciación que al efecto emitan sobre la idoneidad, eficiencia profesional y condiciones del personal, y justifica que sus sesiones y actas sean secretas. En este orden de ideas -concluye la Corte- la "normativa resultaría vulnerada de hacerse públicos los fundamentos de la decisión de incluir al señor Díaz Acuña en Lista de Retiro, pues ello contradice las características que la Constitución y la Ley otorgan a las Fuerzas Armadas en la normativa recién citada, alterando el orden institucional que las rige, desnaturalizándolas en su esencia y, consecuentemente, afectando el interés de la Nación"125.

Similar materia debió ser revisada en "Balmaceda Hoyos con Armada de Chile ${ }^{126}$, donde tras dar cuenta de resuelto en la decisión y sentencia precitadas, el Consejo concluyó que la información relativa a los antecedentes tenidos a la vista para la selección de las personas que forman parte de la lista de retiros, así como su evaluación y ponderación, son reservados a la luz de lo dispuesto por el artículo 26 de la Ley № 19.648 y la afectación de la seguridad de la Nación,

${ }^{123}$ Corte de Apelaciones de Santiago, Sentencia Rol No 1.948-2010, de 8 de marzo de 2011.

${ }^{124}$ Id., cons. $5^{\circ}$.

${ }^{125}$ Id., cons. $6^{\circ}$. La alusión de la Corte al "interés de la Nación" resulta confusa, pues el artículo $8^{\circ}$ CPR conoce de la afectación al "interés nacional" -lo que el artículo $21 \mathrm{~N}^{\circ} 4$ de la Ley de Transparencia ejemplifica refiriéndose a "la salud pública", las "relaciones internacionales" y los "intereses económicos o comerciales del país" - y la argumentación tanto de la FACH como del CplT se refiere a la afectación de la "seguridad de la Nación". Conforme a ello, es dable interpretar que ésta se refiere, en forma general, a la afectación de los intereses colectivos protegidos por el artículo $8^{\circ}$ de la CPR, en particular, la seguridad de la Nación.

${ }^{126}$ CpIT C870-10, cit. n. 116. 
manifestada por el peligro de daño a "el carácter disciplinado y no deliberante de las FF.AA." ${ }^{127}$. Bajo idénticos argumentos, concluyó que también son secretas las apreciaciones de los calificadores de un oficial ${ }^{128}$.

\section{Información financiera de la Defensa y la Ley Reservada del Cobre}

La existencia de leyes secretas en Chile y su validez constitucional parecía un problema que no ocupaba a la doctrina ni la jurisprudencia ${ }^{129}$. Empero, recientes decisiones del CpIT han debido responder a una pregunta hasta ahora irresuelta: ¿es aplicable una norma de secreto contenida en un texto legal secreto? En particular ¿son aplicables aquellas reglas establecidas en la famosa "Ley Reservada del Cobre"?

Según han indicado las decisiones del CplT que revisaremos a continuación, la Ley Reservada No 13.196, del Cobre, de 1958, (en adelante, Ley Reservada del Cobre) tiene por objeto "financiar '...la adquisición de sistemas de armas y pertrechos, es decir, la adquisición y mantenimiento de los materiales y elementos que conforman el potencial bélico nacional...', a través de un gravamen de un $10 \%$ sobre el valor de las exportaciones de cobre y sus derivados que hace la Corporación del Cobre ${ }^{1130}$. Por su parte, el régimen de secreto dispuesto por ella ha sido descrito por el Ministro de Defensa Nacional en los siguientes términos: "su artículo $2^{\circ}$ prescribe lo siguiente: 'Las entregas de fondo que deban realizarse en cumplimiento a lo establecido en el presente decreto ley, se harán en forma reservada; se mantendrán en cuentas secretas, se contabilizarán en forma reservada y su inversión, ya sea en compras de contado o en operaciones de crédito, pago de cuotas a contado o servicio de los créditos, se dispondrá mediante decretos supremos reservados exentos de toma de razón y refrendación $n^{\prime \prime \prime} 131$.

Las particularidades de esta ley han sido estudiadas por el CplT en "Donoso Salgado con Ministerio de Defensa Nacional", con ocasión de la denegación del acceso al "monto empozado en la cuenta de la Ley Secreta del Cobre", sus ingresos, gastos y remanentes entre el año 2004 a $2009^{132}$; y, al mismo tiempo,

${ }^{127}$ CplT C870-10, cit. n. 116 , cons. $12^{\circ}$, a).

${ }^{128}$ CplT C870-10, cit. n. 116 , cons. $12^{\circ}$, d).

${ }^{129}$ Cfr. Contreras, "Transparencia", cit. n. 3, pp. 87-124.

${ }^{130}$ CpIT C396-10, de 2 de noviembre de 2010, "Montt Rettig con Ministerio de Defensa Nacional", cons. $9^{\circ}$, citando el Libro de la Defensa Nacional, p. 303 (énfasis en el original).

${ }^{131}$ CpIT C57-10, cit. n. 38, numeral $4^{\circ}$ de la parte expositiva (énfasis en el original). En similares términos, CpIT C396-10, cit. n. 130, numeral $7^{\circ}$ de su parte expositiva. Sobre el rol fiscalizador de la Contraloría General de la República en la materia, véase su Dictamen № 56.749, de 15 de octubre de 2009.

${ }^{132}$ CpIT C57-10, cit. n. 38, cons. $1^{\circ}$. 
en "Montt Rettig con Ministerio de Defensa Nacional"133 por la denegación del contrato que materializó la adquisición, por trato directo, de un puente mecano instalado en el río Bío-Bío, el que fue adquirido bajo el régimen de la Ley Reservada del Cobre y el Reglamento complementario de la derogada Ley № 7.144, que creó el Consejo Superior de la Defensa Nacional, COSUDENA (D.S. No 124, de 2004, del Ministerio de Defensa Nacional). En este último caso, además, el organismo denegó su acceso arguyendo la aplicabilidad de los artículos 436 CJM y $21 \mathrm{~N}^{\circ} 3$ LT.

Al abordar la materia, en ambas decisiones el Consejo sostuvo que, en virtud de lo dispuesto por los artículos $21 \mathrm{~N}^{\circ} 5$ y $1^{\circ}$ transitorio de la Ley de Transparencia, al revisar esta norma corresponde "verificar: a) Que la ley esté vigente; b) Que, en el caso concreto, la hipótesis o caso de reserva se subsuma dentro de alguna de las causales del artículo $8^{\circ}$ de la CPR, conforme requiere tanto el artículo $21 \mathrm{~N}^{\circ} 5$ de la Ley de Transparencia como su artículo $1^{\circ}$ transitorio. Ello supone revisar si la seguridad nacional se vería afectada por la divulgación de la información solicitada"134. Tales pasos, a nuestro entender, unifican presupuestos que hemos intentado diferenciar, a saber: la reconducción material de la norma de secreto en las causales constitucionales, la subsunción de las circunstancias del caso concreto en la hipótesis legal de secreto y el test de daño.

Tras su acceso al texto actualizado de la Ley Reservada del Cobre ${ }^{135}$, el Consejo expone importantes antecedentes sobre su contenido y forma de aplicación. Primeramente, concluye que la norma "se encuentra vigente, pues fue publicada conforme a su propia redacción en forma diferente a la establecida en el Código Civil y no ha sido derogada", por lo tanto, debe reputarse como una norma legal aprobada con quórum calificado ${ }^{136}$. En segundo lugar, analizando los casos en cuestión, indicó lo siguiente: En cuanto al monto empozado en la cuenta creada por esta ley, ratifica "[q]ue efectivamente la Ley Reservada del Cobre declara secreta la información solicitada [...]", y a continuación agrega -en lo que parece un juicio unificado sobre la reconducción material de la norma en estudio y la conclusión del test de daño sobre la seguridad de

\footnotetext{
${ }^{133}$ CplT C396-10, cit. n. 130.

${ }^{134}$ CplT C396-10, cit. n. 130, cons. $10^{\circ}$ (énfasis agregado). En similares términos, véase CplT C57-10, cit. n. 38, cons. $4^{\circ}-5^{\circ}$, y las decisiones CpIT C349-11 y C536-11 (acumuladas), cit. n. 38, cons. 11 ${ }^{\circ}$.

135 En ambos casos el Consejo requirió al Ministerio de Defensa Nacional, como medida para mejor resolver, el acceso al texto definitivo y actualizado de la Ley Reservada del Cobre, lo que le fue inicialmente negado, pero posteriormente concedido. Véase CpIT C57-10, cit. n. 38, numeral $5^{\circ}$ de su parte expositiva, y CpIT C396-10, cit. n. 130, numerales $4^{\circ}$ y $7^{\circ}$ de su parte expositiva.

${ }^{136}$ CpIT C57-10, cit. n. 38, cons. 7. En similares términos, CpIT C396-10, cit. n. 130, cons. 11º. En ambos casos el Consejo da cuenta que la tramitación de esta ley reservada se habría sujetado a lo dispuesto por los arts. 27, 28 y 29 del D.L. N 991/1976, que establece normas sobre tramitación de los decretos leyes.
} 
la Nación-: "[...] este Consejo estima plausible que su divulgación afectaría la seguridad nacional, en tanto se trata de recursos destinados a la adquisición de material bélico y equipamiento militar [...], conforme ponderó el legislador" ${ }^{\prime 137}$. Por el contrario, sobre el acceso al contrato solicitado, el Consejo resolvió su publicidad, tras desestimar la subsunción del caso concreto en las hipótesis contempladas en ley reservada y en el artículo 436 CJM, así como la afectación de la seguridad de la Nación. Al respecto, señalo lo siguiente:

"[...] el Consejo estima que la Ley № 13.196, Reservada del Cobre, y nuestro ordenamiento jurídico admite el secreto de los documentos relacionados con la adquisición de equipos y pertrechos militares o policiales (art. 436 Código de Justicia Militar), pero no advierte que esta hipótesis concurra en este caso. Por un lado, el Ejército no ha proporcionado a este Consejo elementos de juicio que le hayan permitido formarse esa convicción. Por otro, la información solicitada dice relación con la adquisición e instalación de un puente mecano sobre el río Bío-Bío a raíz del terremoto de inicios de año, puente que se emplazará en paralelo a los otros ya existentes y, además, estará expuesto al público -para el uso de civiles-con lo que sus características serán conocidas por todos. En este contexto el Consejo no aprecia cómo afectaría a la seguridad nacional la revelación de lo solicitado $[\ldots]^{\prime \prime 138}$.

Este último punto fue precisado en la resolución del recurso de reposición administrativo interpuesto en contra de "Montt Rettig con Ministerio de Defensa Nacional"139, indicando expresamente que "si bien la decisión recurrida reconoce la plena vigencia de las normas legales contenidas en el artículo 436 del Código de Justicia Militar y la Ley № 13.196, Reservada del Cobre, [...] la información solicitada en el caso en análisis no se encontraba amparada en ninguna de las hipótesis de reserva legal que dichos preceptos contemplan"140. Además, aprovechó de clarificar una aparente contradicción en las soluciones arribadas en sus decisiones sobre la materia, haciendo presente que en "Donoso Salgado con Ministerio de Defensa Nacional" "se declaró que el monto existente en la cuenta de la Ley Secreta del Cobre se encontraba amparado por la causal de reserva o secreto establecida en la Ley $N^{\circ} 13.196,[\ldots]$ dado que se trataba de recursos destinados a la adquisición de material bélico y equipamiento militar. [...] sin embargo, en este caso la información solicitada no se refiere a equipamiento que revista esa naturaleza"141.

\footnotetext{
137 CplT C57-10, cit. n. 38, cons. $8^{\circ}$.

${ }^{138}$ CpIT C396-10, cit. n. 130, cons. $12^{\circ}$.

${ }^{139}$ CplT C396-10, de 7 de enero de 2011, "Montt Rettig con Ministerio de Defensa Nacional" (resolución de reposición).

${ }^{140}$ Id., cons. $4^{\circ}$.

${ }^{141}$ Id., cons. $10^{\circ}$.
} 
En consecuencia con lo expuesto, debe concluirse que el Consejo ha resuelto que es aplicable la norma de secreto consagrada en la Ley Reservada del Cobre, en tanto en cuanto éste considere que, en el caso concreto, concurre una daño a la seguridad de la Nación -previa aplicación del test de daño-, lo que es consecuencia de la reconducción material de esta norma a las causales constitucionales de secreto.

Cabe destacar que, como obiter dictum, ambas decisiones dejan constancia de la "preocupación" del Consejo "porque en nuestro ordenamiento existan leyes que tienen carácter secreto", pues admitirlas "supone aceptar un peligroso bolsón de opacidad que pugna con el principio constitucional de publicidad y transparencia y el contenido esencial del derecho a acceder a la información pública" así como con el principio democrático y derecho a un debido proceso $^{142}$. Además -agrega el Consejo- "no se ve por qué resulta necesario que la ley misma sea un documento reservado y no simplemente determinada información que la ley señale, como es la regla que establece el artículo $8^{\circ}$ de la Constitución. Por ello, este Consejo oficiará a los órganos colegisladores manifestándoles su preocupación por este estado de cosas"143. Tales observaciones sin duda han servido a la discusión del proyecto de ley que pretende modificar el sistema de financiamiento de las FF.AA. y derogar la Ley Reservada del Cobre ${ }^{144}$.

\section{Información sobre contratos y procesos de adquisición de pertrechos militares}

La prevalencia del secreto en los procesos de contratación de las FF.AA. y las de Orden y Seguridad Pública ha sido una constante en la regulación del acceso a la información. Fiel reflejo de ello es la Ley № 19.886, que regula los contratos de suministros y prestaciones de servicios de la Administración

\footnotetext{
${ }^{142}$ CpIT C57-10, cit. n. 38, cons. $10^{\circ}$. También en CplT C396-10, cit. n. 130, cons. $13^{\circ}$ y $14^{\circ}$.

${ }^{143}$ CplT C57-10, cit. n. 38, cons. $11^{\circ}$. También en CplT C396-10, cit. n. 130, cons. $14^{\circ}$.

${ }^{144}$ El proyecto de ley que establece el "nuevo mecanismo de financiamiento de las capacidades estratégicas de la defensa nacional" (Boletín № 7678-02), originado en mensaje presidencial, de 20 de mayo de 2011, junto con derogar la Ley Reservada del Cobre, sustituye el título VI de la Ley № 18.948, Orgánica de las FF.AA., relativo a su régimen presupuestario. Dicha modificación establecería, por una parte, un sistema de financiamiento de las actividades generales de las FF.AA., cuyo presupuesto, contabilidad y la administración de fondos se ajustaría a las reglas de Administración Financiera del Estado. Además, crearía un sistema de financiamiento de capacidades estratégicas, destinado al financiamiento de la inversión y desarrollo en material bélico, sus gastos de operación y sostenimiento. Dicha inversión y gasto se concretarían en proyectos aprobados por decreto conjunto de los Ministerios de Defensa Nacional y de Hacienda. Sin embargo, por razones de seguridad de la Nación, estos decretos tendrían carácter reservado y estarían exentos del trámite de toma de razón, y, por iguales razones, la fiscalización y control de Contraloría General de la República sobre la inversión y gastos se realizaría en forma reservada.
} 
del Estado y exceptúa de las obligaciones de publicidad contenidas en ella a los contratos que versen sobre el difuso concepto de "materiales de guerra"145 y los celebrados en virtud de la Ley Reservada del Cobre y la derogada Ley № 7.144, de 1942, que creó el Consejo de Seguridad Nacionales [esta última autorizaba al Presidente de la República la contratación de "elementos destinados a la Defensa Nacional"]. Además, dicho cuerpo normativo autoriza a las FF.AA., de Orden y Seguridad Pública a mantener registros secretos de sus contratistas y remite el régimen de publicidad de sus contrataciones a "su legislación vigente sobre manejo, uso y tramitación de documentación" -sobre la que ya nos hemos pronunciado en supra III.1-. Sin embargo, desde el año 2010 debe incorporarse a este conjunto normativo -y a su interpretación- el artículo 34 de la Ley № 20.424, que aprueba el Estatuto Orgánico del Ministerio de Defensa Nacional. Dicha norma, contrariamente a lo indicado por la citada Ley $N^{\circ} 19.886$, ordena que "[l]os registros de proveedores de los organismos e instituciones del sector serán públicos"146, y declara un nuevo objeto de secreto en nuestra legislación, a saber: "Los fundamentos de los actos y resoluciones presupuestarios de la defensa nacional" en lo relativo a los campos que indica, entre ellos, las "especificaciones técnicas y cantidades de equipamiento bélico y material de guerra"147. Este grupo de disposiciones, así como artículo 436 CJM, constituyen el fundamento del secreto de los procesos de contratación de las instituciones de la defensa nacional, y así lo han argumentado éstas en los casos que revisaremos a continuación.

En efecto, estas fueron las cuestiones jurídicas a revisar en "Weatherhaven Chile S.A. con Estado Mayor Conjunto"148, donde el Consejo concluyó que son públicos: (a) Los antecedentes de un proceso licitatorio destinado a proveer a una fuerza de paz chileno-argentina de un "sistema de habitabilidad", compuesto por contenedores, carpas y suministros de agua y energía [el valor de las

\footnotetext{
145 Para revisar algunos ejemplos de lo que el legislador ha entendido como pertrechos militares, así como de material bélico, véase Ley $\mathrm{N}^{\circ} 19.924$, de 2004, que modifica la normativa relativa a la importación de las mercancías del sector defensa calificadas como "pertrechos".

${ }^{146}$ A nuestro entender, de conformidad con el artículo $3^{\circ}$ transitorio de la Ley $N^{\circ} 20.424$, el citado artículo 16 de la Ley № 19.886 debe, en lo pertinente, entenderse derogado.

147 Inciso primero del artículo 34 de la Ley No 20.424: "Los fundamentos de los actos y resoluciones presupuestarios de la defensa nacional, incluidos los que acompañan el proyecto de Ley de Presupuestos del Sector Público, serán secretos o reservados en todo lo relativo a: a) Planes de empleo de las Fuerzas Armadas; b) Estándares en los que operan las Fuerzas Armadas; c) Especificaciones técnicas y cantidades de equipamiento bélico y material de guerra; d) Estudios y proyectos de inversión institucionales o conjuntos referidos al desarrollo de capacidades estratégicas. Asimismo, los gastos institucionales y conjuntos de las Fuerzas Armadas para los efectos de la Ley № 19.974 [sobre el sistema de inteligencia del Estado] serán secretos".

${ }^{148}$ CpIT C349-11 y C536-11 (acumuladas), cit. n. 38.
} 
ofertas, el contrato de adquisición celebrado, el nombre del fabricante, etc.]; y (b) Las especificaciones técnicas del equipamiento adquirido, tales como su carga admisible y su resistencia transversal y de apilamiento. Para resolver el caso, en primer lugar, la decisión concentró su atención en identificar los niveles de acceso a información del procedimiento licitatorio, a fin de desvirtuar el potencial dañino de su comunicación. Ello le permitió verificar que el Reglamento Complementario de la derogada Ley $\mathrm{N}^{\circ} 7.144^{149}$ distingue 4 procedimientos para la adquisición de elementos destinados a la Defensa Nacional, a saber, "propuesta pública, privada, trato directo o secreto"150, y que el Servicio optó por el primero de ellos. Tal constatación le permitió concluir "que el procedimiento [...] permitió la participación de cualquier oferente, lo que posibilitó a cualquier tercero -incluso un adversario hipotético- acceder a antecedentes propios de la licitación, lo que, por sí mismo, desvirtúa el potencial dañoso para la seguridad de la Nación -exigido por los artículos 436 del CJM y 21 N $^{\circ} 3$ de la Ley de Transparencia- $[. . .]^{\prime 151}$. Tal aserto fue compartido por la Corte de Apelaciones de Santiago al revisar el reclamo de ilegalidad deducido por el Estado Mayor Conjunto en contra de la precitada decisión del CplT, concluyendo que "resulta difícil de entender que, después de adoptada la decisión de convocar a una licitación pública para contratar la adquisición mencionada, y una vez celebrado el contrato, el Estado Mayor Conjunto invoque el carácter secreto o reservado de la operación sobre la cual se requirieron los datos por la vía del amparo, denegando el acceso a la información pedida"152.

En segundo lugar, al revisar el potencial dañino de la comunicación de las especificaciones técnicas del equipamiento adquirido, la decisión del Consejo se concentra en determinar el contenido del art. 34 de la Ley № 20.424 -deslindándolo del art. 436 CJM y su concepto de "pertrechos"-. Esta labor le lleva a concluir que esta hipótesis de secreto restringe su ámbito de aplicación "a aquellos equipamientos y materiales que, producto de las especiales particularidades de sus especificaciones técnicas, su divulgación afectaría la seguridad de la Nación, lo que exigiría verificar en las circunstancias del caso concreto, si concurren o no dichas particularidades técnicas" ${ }^{\prime 153}$. Tal aserto parece indicar que, a ojos del CplT, no basta la subsunción de la información requerida en el

\footnotetext{
${ }^{149}$ Cuerpo normativo vigente por expresa disposición del artículo $3^{\circ}$ transitorio de la Ley № 20.424 y que fuere enviado por el Estado Mayor Conjunto al CpIT "bajo reserva". Véase CpIT C349-11 y C53611 (acumuladas), cit. n. 38, número 8 de la parte expositiva.

${ }^{150}$ CplT C349-11 y C536-11 (acumuladas), cit. n. 38, cons. $13^{\circ}$.

${ }^{151}$ CpIT C349-11 y C536-11 (acumuladas), cit. n. 38, cons. $14^{\circ}$.

${ }^{152}$ Corte de Apelaciones de Santiago, Sentencia Rol No 7.497-2011, de 24 de mayo de 2012. Cons. $8^{\circ}$.

${ }^{153}$ CplT C349-11 y C536-11 (acumuladas), cit. n. 38, cons. 16º letra b).
} 
concepto de "especificación técnica" para que proceda su secreto, sino que también deberá verificarse, bajo el estándar probatorio del test de daño, que la comunicación de esas "especiales particularidades" afectaría la seguridad de la Nación. En este orden de ideas, el CpIT desestima la concurrencia de tal daño fundado en que: (a) se trataría de especificaciones técnicas de productos de "uso común en el ámbito civil", (b) su comunicación no comprometería la "seguridad operativa" de la misión de paz a la que se encuentran destinados; (c) la vía elegida por el organismo para su adquisición permite el acceso de cualquier oferente a las características de los productos demandados; y (e) los equipos serían puestos a disposición de otros Estados, así como ante un organismo internacional, lo que permitirá el acceso irrestricto de terceros Estados a sus características y especificaciones ${ }^{154}$.

Con anterioridad a la decisión citada, en "Serani Mostazal con Carabineros de Chile ${ }^{\prime \prime 155}$ el CplT debió determinar si un contrato de prestación de servicios de telefonía celebrado entre dicha institución y la empresa telefónica Entel era susceptible de la reserva consagrada por el artículo 436 CJM. Ello fue desestimado tras revisar la subsunción de la información en las diversas acepciones del concepto de "pertrechos" en el Diccionario de la Real Academia Española, destacar la amplitud de las mismas y recordar la necesidad de interpretar restrictivamente las limitaciones del DAIP ${ }^{156}$. Hecho esto, la decisión no avanza en verificar que la comunicación afecte la seguridad de la Nación conforme al test de daños, por no superar su presupuesto previo: la subsunción. En similares términos se pronunció el Consejo en "Montt Rettig con Ministerio de Defensa Nacional" respecto del contrato que materializó la adquisición del puente mecano instalado en el río Bío-Bío, pues, según se lee en ella, "el contrato por el cual se adquirió el puente mecano objeto de esta solicitud -que será de uso público- y sus antecedentes fundantes no caben dentro de ninguno de los numerales del artículo 436 del Código de Justicia Militar [...]"157.

\section{Información sobre operaciones militares}

También ha correspondido al Consejo revisar el carácter secreto de los antecedentes de vuelo de misiones aéreas de entrenamiento e instrucción en aviones de combate de la $\mathrm{FACH}$, modelo F-16, que son entregados por ésta

\footnotetext{
${ }^{154}$ CplT C349-11 y C536-11 (acumuladas), cit. n. 38, cons. $17^{\circ}$.

155 CplT C453-10, cit. n. 61.

${ }^{156}$ CplT C453-10, cit. n. 61, cons. 10. Conclusión ratificada en CplT C453-10, de 11 de marzo de 2011, "Serani Mostazal con Carabineros de Chile" (resolución de reposición), cons. $4^{\circ}$ y $5^{\circ}$.

${ }^{157}$ CplT C396-10, cit. n. 130, cons. 8 . Criterio ratificado en CplT C396-10, de 7 de enero de 2011, "Montt Rettig con Ministerio de Defensa Nacional" (resolución de reposición).
} 
a la Dirección General de Aeronáutica Civil (DGAC). Ello fue lo debatido en "Sagredo Stevens con Dirección General de Aeronáutica Civil"158, con ocasión de la solicitud formulada por un piloto civil que -según indico la $\mathrm{FACH}$ - fue objeto de una "reconocimiento visual" por estas aeronaves, mientras sobrevolaba una zona restringida. El asunto es resuelto por el Consejo con especial deferencia a lo expuesto por la Dirección General de Aeronáutica Civil (DGAC) y la $\mathrm{FACH}$, al punto de reproducir sus alegaciones en sus consideraciones. En efecto, la decisión señala que "el conocimiento de la información de vuelo de las aeronaves militares [...] «... permitiría obtener información sensible respecto de las características del entrenamiento que se está impartiendo a los pilotos de combate, la duración de dichas misiones, y en general a las performances del material de combate institucional y el rendimiento que de este material obtiene la institución (velocidades en que se realizan los entrenamientos, alturas máximas o mínimas de estos, autonomía de los vuelos, número de aeronaves que participan en ellos, etc.) »"159.

Esta decisión representa un ejemplo ilustrativo, aunque excepcional, de consideración a la posición privilegiada de la administración para proyectar las consecuencias dañinas de la publicidad en determinadas materias: las particularidades técnicas y estratégicas de las operaciones de las aeronaves sobre las que versaba la solicitud. En ese sentido, el CplT concluyó que "analizados los descargos formulados tanto por la DGAC como por la FACH [...] de las alegaciones de esta última se desprende una expectativa razonable de afectación de la defensa nacional en caso de revelarse la información solicitada [...], pues permitiría conocer antecedentes relevantes de las operaciones militares desarrolladas por las aeronaves [...]. Para ello se tiene presente, además, que la defensa de este bien jurídico es parte consustancial de la esfera competencial de dicho organismo"160.

Además, la decisión incorpora un incipiente pronunciamiento sobre la proporcionalidad de la medida de secreto, inclinándose por su eficacia: "mantener la reserva de la información solicitada es la medida más eficaz para proteger el desarrollo de las operaciones militares de las aeronaves de guerra aludidas, así como de la $\mathrm{FACH}, \mathrm{y}$, por lo tanto, para resguardar la defensa nacional y, con ello, la seguridad de la Nación" ${ }^{\prime 161}$.

${ }^{158}$ CplT C159-11, cit. n. 75.

${ }^{159}$ CpIT C159-11, cit. n. 75, cons. $6^{\circ}$ (énfasis en el original).

160 Ídem, cons. $9^{\circ}$.

${ }^{161}$ CpIT C159-11, cit. n. 75 , cons. $10^{\circ}$. Al efecto, la decisión se remite al criterio acordado en "De la Carrera Valdés con Carabineros de Chile" -véase supra III.2-. 


\section{REFLEXIONES FinALES}

1. Es claro que el interés por la contingencia constituye un importante motor para el ejercicio del derecho de acceso a la información. Por ejemplo, el mismo día en que el Ministro del Interior descartaban los efectos nocivos de las bombas lacrimógenas utilizadas por Carabineros de Chile, un ciudadano solicitaba los informes técnicos en que fundaba su pronunciamiento ${ }^{162}$. Sin embargo, el potencial del DAIP como elemento de accountability o rendición de cuentas del accionar estatal es proporcional a la vastedad de los archivos conservados por el Estado. Lamentablemente, aunque no por coincidencia, los regímenes que han dado forma a la regulación archivística nacional en 1929 y 1989 han abogado por perpetuar la discrecionalidad de su administración, lo que hasta ahora no ha sido enmendado. Si bien el Consejo para la Transparencia no posee las competencias necesarias para forzar un cambio institucional en la materia, la adopción de estándares que justifiquen la inexistencia de información como causal de denegación ha permitido contrastar las alegaciones de los servicios, minimizando los riesgos de su invocación indiscriminada. Ello no obsta a que en el ejercicio de sus potestades normativas ${ }^{163}$ el CpIT invite a la modificación del sistema reglamentario de archivo y eliminación de documentos de las instituciones de la defensa nacional, ya sea para incorporar estas instituciones al régimen común de archivo y destrucción, lo que requeriría reformar el D.F.L. № 5.200, de 1929, o unificar sus distintos regímenes en un único cuerpo especial, para lo que bastaría la modificación de sus reglamentos internos -los que, paradójicamente, las instituciones califican como secretos-.

2. La jurisprudencia revisada permite concluir que el denominado test de daño, por una parte, opera como un mecanismo de corrección normativa, mediante la reconducción material de las hipótesis legales de secreto a la causal constitucional que le sirve de matriz, esto es, la afectación de la seguridad de la Nación. Tal hermenéutica parece reaccionar a la vigencia de hipótesis legales de secreto previas a la reforma constitucional de 2005, cuya tipicidad abierta -particularmente la del art. 436 CJM- requiere ser delimitada de cara al principio de publicidad constitucional. Aun cuando la vaguedad de las hipótesis legales pre-2005 y la ausencia en la Ley de Transparencia de un desarrollo de las causales constitucional restringen las posibilidades del CpIT para obrar de otra forma, en tal ejercicio no debe desatenderse que el artículo $8^{\circ} \mathrm{CPR}$ reserva

\footnotetext{
162 Véase CpIT C738-11, de 2 de septiembre de 2011, "Duhart González con Ministerio del Interior".

${ }^{163}$ Artículo 33, letras d), f) y e), de la Ley de Transparencia. Sobre las potestades del CpIT, véase RAJEVIC MOsLer, Enrique, "El Consejo para la Transparencia como Administración Independiente", en Letelier, Raúl y RAJEVIC, Enriqu (coords.), Transparencia en la Administración Pública, LegalPublishing, Santiago de Chile, 2010, pp. 231-248.
} 
la declaración del secreto al legislador y no a la administración. La adopción de presupuestos uniformes y claros al tiempo de revisar las normas de secreto, así como la formación de "precedentes" sobre lo que deberá entenderse por seguridad de la Nación en clave de acceso a la información, son elementos que permitirán dotar de certeza a los operadores jurídicos ante el Consejo y las Cortes, minimizando los riesgos de discrecionalidad en el actuar del propio Consejo.

3. El test de daño propiamente tal, a su vez, constituye un estándar de argumentación frente a las alegaciones de secreto, dirigido a especificar el daño alegado, su magnitud y la expectativa probable de su ocurrencia. Este resulta especialmente operativo frente a hipótesis legales de tipicidad amplia o abierta, tales como el art. $436 \mathrm{CJM}$ o los casos de secreto consagrados en el artículo 21 de la Ley de Transparencia (que se limitan, con cambios menores, a reproducir la Constitución). Sin embargo, ante disposiciones legales en que el objeto del secreto resulta claro, siendo incuestionable la subsunción del caso concreto a la hipótesis legal, así como la posición adoptada por el legislador en la materia, el test no parece del todo operativo para el Consejo. Tal comportamiento, creemos, responde a que en dichos casos el legislador ha valorado con precisión la afectación de la causal constitucional en la hipótesis legal respectiva -especialmente respecto de hipótesis legales post-2005-, no pudiendo el Consejo sino seguir su mandato. Sin embargo, cabe reconocer la escasés de tipos legales de estas características. En efecto, no debe olvidarse que corresponde al legislador tipificar los casos de secreto y reserva de información en poder de la Administración, de conformidad con las causales constitucionales, por lo que éste no debe descansar en el CplT, ni en las Cortes de Apelaciones, la determinación del contenido de conceptos jurídicos indeterminados, tales como la seguridad de la Nación o el interés nacional.

4. El CplT ha sido perentorio en que la excepcionalidad del secreto en nuestro ordenamiento jurídico exige a los operadores jurídicos una exhaustiva argumentación de la procedencia de las hipótesis de secreto. Sin embargo, en los hechos, las instituciones de la defensa nacional han obviado desarrollar los conceptos de sus disciplinas que dan forma a las normas de secreto y justificar su finalidad particular (v.gr., qué se entiende por pertrechos militares o material bélico o "planificación militar o estratégica"164), al punto que tienden al silencio cuando les corresponde explicitar la cadena de consecuencias nocivas que involucraría la publicidad de la información en cada caso o extreman al

${ }^{164}$ El artículo 22 de la LT dispone que el carácter secreto o reservado de cierta información será indefinido, "tratándose de los actos y documentos que, en el ámbito de la defensa nacional, establezcan la planificación militar o estratégica $[\ldots] "$ ". 
absurdo su amplitud -v. gr., han llegado a estimar secreto el reglamento de uno de sus clubes recreacionales ${ }^{165}$-. Frente a tal escenario, no es de extrañar que el Consejo aborde el sentido de estas disposiciones sin consideración a las particulares definiciones militares o estratégicas que debiese existir al interior de las instituciones de la defensa nacional (lo que explica la revisión del concepto de pertrechos desde el "uso general de las palabras") y que en el futuro rehúya de actuar deferentemente con la administración al tiempo de calificar el impacto de la publicidad en la seguridad de la Nación, aunque, teóricamente, ésta posea una posición privilegiada para evaluar la consecuencias de la comunicación de información en la seguridad de la Nación.

5. La temprana asimilación del juicio de proporcionalidad con la aplicación complementaria del test de interés público y el denominado test de daño $o^{166}$, parece explicar que la jurisprudencia del CplT aquí revisada abunde en referencias al "interés público" de divulgar la información cuyo secreto se controvierte, no obstante las cuestiones jurídicas a resolver se centren en descartar el daño a la seguridad de la Nación invocado por el organismo. Clarificar el alcance conceptual de ambos test y sus presupuestos contribuiría a la predictibilidad de sus decisiones.

${ }^{165}$ CplT C669-10, de 2 de noviembre de 2011, "Jeanne Moreau Caro con FACH".

166 Véase supra III.4. 